\title{
Review Article \\ Neuroplasticity Underlying the Comorbidity of Pain and Depression
}

\author{
Lisa Doan, ${ }^{1}$ Toby Manders, ${ }^{1}$ and Jing Wang ${ }^{1,2}$ \\ ${ }^{1}$ Department of Anesthesiology, New York University School of Medicine, New York, NY 10016, USA \\ ${ }^{2}$ Department of Neuroscience and Physiology, New York University School of Medicine, New York, NY 10016, USA \\ Correspondence should be addressed to Jing Wang; jing.wang2@nyumc.org
}

Received 5 December 2014; Accepted 10 February 2015

Academic Editor: Geun Hee Seol

Copyright (c) 2015 Lisa Doan et al. This is an open access article distributed under the Creative Commons Attribution License, which permits unrestricted use, distribution, and reproduction in any medium, provided the original work is properly cited.

\begin{abstract}
Acute pain induces depressed mood, and chronic pain is known to cause depression. Depression, meanwhile, can also adversely affect pain behaviors ranging from symptomology to treatment response. Pain and depression independently induce long-term plasticity in the central nervous system (CNS). Comorbid conditions, however, have distinct patterns of neural activation. We performed a review of the changes in neural circuitry and molecular signaling pathways that may underlie this complex relationship between pain and depression. We also discussed some of the current and future therapies that are based on this understanding of the CNS plasticity that occurs with pain and depression.
\end{abstract}

\section{Introduction}

Pain encompasses sensory, cognitive, and most importantly affective components. The affective component of pain includes feelings of annoyance, sadness, anxiety, and depression in response to a noxious stimulus. In particular, depression and pain share a high degree of comorbidity, and a large number of studies have examined the close relationship between pain and depression.

Acute pain can adversely affect mood following surgery. In the immediate postoperative period, the rate of depression has been reported to be between 21 and $50 \%$ in study populations with low (0-11.8\%) levels of preoperative depression. Indeed, postoperative pain intensity is correlated with the degree of depressive symptoms [1-3]. High postoperative depression scores have also been associated with increased length of stay and poor functional outcomes after surgeries $[3,4]$. Preoperative psychological factors may also negatively affect the resolution of acute pain. Preoperative anxiety and catastrophization are two well-studied risk factors for the development of chronic postsurgical pain [5]. Both of these factors are known to lead to worsening depressed mood in the postoperative period.
Chronic pain and comorbid depression are frequently encountered clinically. In patients treated for depression, the prevalence of chronic pain is reported to be $51.8-59.1 \%$ [68]. Longitudinal studies have shown that depression is a risk factor for the onset of disabling or chronic pain $[9,10]$. Conversely, in patients with chronic pain, the mean prevalence of major depression is reported to be between 18 and $85 \%$, depending on the practice setting $[11,12]$. In fact, pain is a major risk factor for the development of depression. In a longitudinal, cohort study with 12-year follow-up, pain at baseline as well as the severity and chronicity of pain was statistically significantly associated with the onset of depression [13].

Pain adversely affects the prognosis and treatment of depression and vice versa. There is a significant correlation between the severity of pain and the degree of depression [14]. In a study examining the long-term course of depression, greater severity of pain at baseline, greater number of pain locations, and longer duration of pain all significantly increased the risk of still having depression after two years [15]. Baseline pain severity prior to the initiation of antidepressant treatment has also been shown to be a strong negative predictor of treatment response [16]. At the same time, 
depression also adversely affects prognosis in the treatment of chronic pain. Patients with chronic pain and depression report more pain complaints and increased severity and longer duration of pain symptoms [16]. Some studies have reported that patients with comorbid pain and depression have poorer response to pain treatment than nondepressed patients [17]. Comorbid pain and depression also lead to significant functional impairments. In a cross-sectional study, patients with major depressive disorder with chronic pain are found to be 2.1-4.6 times more likely to report interference in activities of daily living and family and social interactions than depressed patients without pain. They have also been found to be more likely to take sick leave because of pain [18].

Thus, a wealth of clinical data suggests a high degree of comorbidity between pain and depression. Basic and translational studies utilizing imaging as well as animal models have begun to unravel the mechanistic basis for the relationship between pain and depression. In this review, we will examine the current understanding of the circuit and molecular plasticity that underlie this complex relationship and how such understanding can lead to successful therapies.

\section{Neuroimaging Evidence for the Plasticity of Pain and Depression Networks}

2.1. Identification of Pain and Depression Circuits Based on Human Imaging Studies. In imaging studies of acute experimental pain in human subjects, areas most commonly activated include the primary somatosensory (S1) and secondary somatosensory cortex (S2), anterior cingulate cortex (ACC), insular cortex (IC), prefrontal cortex (PFC), thalamus, nucleus accumbens (NAc), and amygdala [19-21]. $\mathrm{S} 1$ and $\mathrm{S} 2$ activations contribute to the sensory-discriminative dimension of pain. The ACC, PFC, IC, NAc, and amygdala, meanwhile, have been implicated in the affective component of pain (Figure 1). Distinct alterations in brain structure and activity, meanwhile, occur with chronic pain. For example, reductions in gray matter volume are observed in the IC, ACC, and PFC, areas involved in the emotional and cognitive aspects of pain [22].

Several studies have also directly examined brain changes in the transition from acute to chronic pain. Brain activity in patients with back pain for approximately two months showed activations in the IC, thalamus, ACC, and PFC [23]. In patients with back pain for more than ten years, meanwhile, abnormal activations in the perigenual ACC, medial PFC ( $\mathrm{mPFC}$ ), and amygdala are observed in response to pain. Thus, the transition from acute to chronic pain may be accompanied by a shift from the sensory to affective-emotional circuitry for pain [24]. Additionally, functional connectivity of the NAc with the PFC has been found to be higher in patients with persistent back pain, indicating that the reward circuitry may also play a role in this switch from sensory to affective focus in chronic pain $[23,24]$.

Interestingly, the regions and circuits identified in acute and particularly chronic pain studies closely mirror those found in studies of depression. Thus, areas most commonly found to be dysregulated in depressed patients include the
PFC, ACC, NAc, hippocampus, and amygdala [25, 26]. Gray matter volume loss and alterations in activity have been found in these areas, similar to changes that occur with chronic pain. The PFC and ACC are both involved in the processing of negative mood and affect and thus are implicated in depression studies. The NAc, in addition, may be involved in symptoms such as anhedonia. The hippocampus and amygdala, meanwhile, play roles in the formation and retrieval of negative emotional memory that is associated with pain and depression.

More recently, fMRI studies of resting state networks, during task-free settings, have been done to examine changes in patients with chronic pain and depression. Compared to healthy controls, the default mode network (DMN) is altered in patients with chronic pain, with greater representation in the precuneus and posterior cingulate cortex and less representation in the PFC [27]. Correlation of the PFC with the IC is increased, and connectivity of the PFC with posterior portions of the DMN is decreased in patients with chronic pain. The DMN consists of a set of brain regions active at rest and deactivated during a task. The precise function of the DMN is unclear, but it may be involved in the regulation of attention and arousal. Altered connectivity of the mPFC and IC may reflect changes in emotional circuits associated with chronic pain [27]. Similar changes in the DMN are also seen in depressed patients. For example, in a resting state fMRI study of depressed patients, patterns of functional connectivity in the DMN and affective network based on multivariate pattern analysis are distinct between depressed patients and healthy controls. Thus, connections involving the PFC and ACC are most likely to be altered in the comorbidity between chronic pain and depression [28].

\subsection{Brain Imaging of Physical and Emotional Pain. It is} thought that the concept of suffering is central to the experience of pain as well as the experience of depression [29-31]. Hence, depression has been interpreted as a state of being emotional as opposed to physical pain. A number of imaging studies have addressed this possibility. In healthy subjects, the pattern of brain activity observed with emotional pain, such as intense social rejection which is known to cause depressed mood, is similar to activations in response to exposure to experimental pain, including somatosensory as well as affective areas $[32,33]$. A recent study, however, suggests that although there is commonality at the gross anatomical level, distinct networks may actually underlie acute physical versus emotional pain [34]. This study finds that experimental pain and intense social rejection activated similar brain regions in human subjects, including S2, IC, thalamus, and periaqueductal gray (PAG). However, multivariate pattern analysis showed distinct physical and emotional representations in these regions. Nevertheless, some shared representations were found in areas not primarily involved with sensory pain processing, including the left parahippocampal and fusiform gyri, retrosplenial cortex, posterior cingulate cortex, and striatum. These shared representations may thus be associated with behavioral context, memory, and motivation, and they may form the network link between depression and pain [35]. 
There is evidence that depressed mood or other negative emotional states can also modulate sensory neural responses. In an fMRI study, subjects were exposed to nonpainful visceral stimulation during neutral and negative emotional contexts. Significantly greater activations were noted in the ACC and anterior IC during increasingly greater negative emotional contexts and greater levels of reported anxiety that is commonly found in depressed patients [36].

\subsection{The Complexity of the Chronic Pain and Depression Net-} works. The interaction between chronic pain and depression is likely more complex than assessing acute, experimental conditions. As noted above, in the transition from acute to chronic back pain, a shift from nociceptive to emotional circuitry has been observed [24]. Similar brain regions may be dysregulated in both chronic pain and depression, including areas involved in emotional and reward processing such as the ACC, IC, PFC, and NAc. The DMN is altered in chronic pain and depression. However, in their study of patients with chronic pain, Baliki et al. investigated the effect of comorbid depression on spatial and connectivity properties of resting state networks and found only low correlations between depression and their network connectivity measurements [27]. Further investigation is thus required to explore the relationship between chronic pain and depression at the circuit level. Depressive symptomatology has a wide spectrum, and different brain areas may regulate different symptom clusters. Similarly, chronic pain varies in etiology and disability, and different conditions may have distinct links with depressive symptomatology.

\section{Animal Models for the Study of Pain and Depression}

Whereas imaging studies have established evidence of plasticity at the anatomic and circuit level that underlie the relationship between pain and depression, they do not reveal mechanistic insights into the cause and effect relationship between changes in neurocircuitry and the pathology of pain and depression. Rodent models, on the other hand, have enabled preclinical investigation into the mechanisms and symptoms of pain-induced depression. Two well-developed behavioral assays for depression in rodents are the sucrose preference test (SPT) and the forced swim test (FST) [37]. The SPT is an assay for anhedonia, a salient feature of clinical depression. The SPT involves measuring animals' preference for sucrose solution compared with water. Rodents naturally prefer sucrose over water. Depressed rodents, however, display a decreased preference for sucrose and hence symptoms of anhedonia. The FST, meanwhile, assesses behavioral despair, another important feature of depression. On this test, a rodent is placed into a water tank for fifteen minutes. It is then returned to the same tank 24 hours later. If the rodent is depressed, it will display a decreased motivation to swim during the second session. Other related tests that can be used to test depression-like behaviors include the open field test, elevated plus maze, and novelty-suppressed feeding test which are assays for anxiety-like behaviors that often accompany depression. Another behavioral assay, the conditioned place avoidance/preference test (CPA/CPP), allows additional insight into the aversive and motivational aspects of animals in pain or depressed states. In the CPA and CPP, an animal with no preexisting preference is trained to associate one chamber in a two-chamber set with either a rewarding or aversive stimulus, such as pain and or pain relief, or a pro- or antidepressant, and to associate the other chamber with the control condition. After a period of associative training, the animal is then allowed to freely choose the chamber it prefers or avoids. This test has been used to test the efficacy of both antidepressants and analgesics [38-41].

Models for depression and pain are both very well established [37, 42-45]. On the one hand, widely accepted models for depression already rely on pain as a stressor to induce depression-like symptoms. In the social defeat model, for example, smaller animals are subjected to physical interactions with larger, more aggressive individuals, and pain resulting from such aggressive physical interactions plays an important role in inducing subsequent depression-like behaviors $[37,46,47]$. In a study combining the social defeat model with a neuropathic pain model in rats, five-day exposure to social stress was found to ameliorate pain sensitivity in chronic pain, but ten-day exposure worsened pain thresholds [46]. Conversely, a study in which mice were housed in either an impoverished or enriched environment after developing chronic neuropathic pain symptoms demonstrated that the enriching environment improved chronic pain symptoms [48].

At the same time, current rodent models for pain, including acute and persistent pain models, have been shown to induce depression-like behaviors. Incision models appear to mimic acute surgical pain in humans [43]. Incisions penetrating the skin, fascia, and muscle, such as the plantar incision model using the rodent hind paw, the gastrocnemius incision model using the posterior surface of the rodent hind limb, and the tail incision model, reliably induce allodynia, a pain behavior in response to a nonnoxious stimulus [5]. Moreover, hyperalgesia, increased sensitivity to a noxious stimulus, can develop around the site of the incision. Acute incisional pain has been suggested to induce temporary depressionlike symptoms as manifested by decreased sucrose preference, and these depressive symptoms resolve in a time frame similar to that of the recovery of sensory symptoms [49].

Persistent pain models are capable of inducing longer lasting depressive symptoms. An inflammatory model of pain, in which complete Freund's adjuvant (CFA) is injected into the hind paw in rodents, reliably induces sensory symptoms of chronic inflammatory pain lasting at least two weeks [44]. This CFA model has also been shown to induce depressionlike symptoms. After CFA injection, rats with inflammatory pain have been found to show significantly diminished sucrose preference compared to control animals, and this depressive phenotype can last at least two to five weeks [50, 51]. In addition, CFA-treated rats can also develop behavioral despair, another feature of depression $[52,53]$. Finally, inflammatory pain has been shown to induce place avoidance in rats $[54,55]$. In this test, rats stayed away from the 
chamber associated with inflammatory pain, suggesting that pain serves as an aversive stimulus that the rats actively avoid. Similarly, acute or repeated stress has been shown as an aversive stimulus in the CPA test in a number of rodent depression studies $[37,56]$. Thus, studies using the CPA have demonstrated that pain, similar to psychological stressors known to cause depression, can serve as powerful aversive signals to alter behavior.

Chronic neuropathic pain models mimic human chronic pain-induced depression more closely than acute or inflammatory pain. The most commonly used models of neuropathic pain employ peripheral nerve injury, and these include the chronic constriction injury (CCI), by which ligatures are wrapped around the sciatic nerve, the sciatic nerve ligation model (SNL) of mononeuropathy, by which the L4 spinal nerve is ligated, and the spared nerve injury (SNI) model, by which two of the three terminal branches of the sciatic nerve, the tibial and common peroneal nerves, are axotomized [42, 57]. SNI has been shown to induce anhedonia as well as behavioral despair in rats, as measured by the SPT and FST $[49,58]$. Certain types of pain treatment, meanwhile, have been shown to decrease these depressive symptoms [53]. SNL, likewise, has been shown to cause depressive symptoms as well as anxiety in rodents $[59,60]$.

Thus, animal models for depression have already employed pain as an element of stress to induce depressive symptoms. More importantly, various rodent pain models have been validated to induce depression-like behaviors and hence serve as valuable models for the study of the comorbidity between pain and depression.

\section{Neurocircuit Plasticity That Underlies the Comorbidity of Pain and Depression}

The advancement of modern systems-level neuroscience tools has enabled the identification of brain regions involved in pain and depression processing and the investigation into their structure and function. Pain is a complex, multidimensional experience that involves the potential recruitment of a large, bilateral network of brain regions. These components may become activated dynamically depending on a number of factors: context, stimulus, cognition, and emotion [22, 61]. Recent efforts to identify a so-called pain signature have resulted in the identification of regions which are most essential to experiencing pain. These regions include the thalamus, the cortex, including the ACC, IC, S1, S2, NAc, and the PAG $[19,21]$. A much larger system involves the function of subsystems which include the descending pain modulatory system comprised of the PAG and rostral ventromedial medulla (RVM), as well as the reward-motivation network, including the PFC, NAc, and the ventral tegmental area (VTA). Not surprisingly, this interconnected group of brain regions also forms the basis for understanding the pathophysiology of depression [25].

Preclinical studies focusing on the affective consequences of neuropathic pain have begun to link the aforementioned circuit changes with behavior outcomes in pain states. These studies have provided insights into the potential function

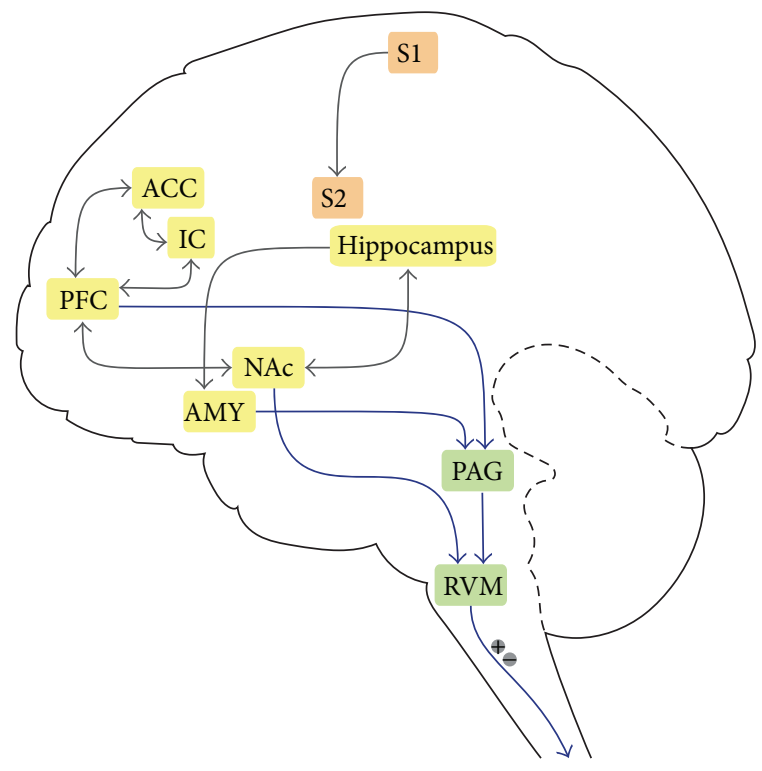

$\longrightarrow$ Descending pain modulation pathway.

$\longrightarrow$ Circuits that modify depressive symptoms of pain.

$\ominus \oplus$ "on" cells in the RVM facilitate pain; "off" cells inhibit pain.

Affective-motivational regions.

Sensory-discriminative regions.

FIGURE 1: Brain regions and circuits implicated in the comorbidity between pain and depression. ACC: anterior cingulate cortex; AMY: amygdala; IC: insular cortex; NAc: nucleus accumbens; PAG: periaqueductal gray; PFC: prefrontal cortex; RVM: rostral ventromedial medulla; S1: primary somatosensory cortex; S2: secondary somatosensory cortex.

of regions involved in the anxio-depressive components of chronic pain-most notably, the ACC, IC, hippocampus, amygdala, the NAc, and the VTA (Figure 1) [62]. The ACC, which processes cognitive, emotional, and autonomic functions and interacts with the thalamus and amygdala, has been implicated in both pain processing and depression [63, 64]. Hypermetabolism and diminished volume of the ACC have both been observed in depressed patients and ACC changes, including altered membrane potential oscillations, have separately been observed in the CCI neuropathic pain model [65]. Recruitment of the ACC may play multiple roles in the experience of pain and pain-induced depression, from anticipation to aversion. In the SNI neuropathic pain model, for example, the volume of the ACC was found to diminish only after a delay, at the same time as the onset of anxiodepressive symptoms, suggesting that structural changes in the ACC potentially represent certain depressive changes in response to pain [66]. The ACC response to pain, moreover, has been shown to be potentiated by amputation [67]. Lesion studies have moreover confirmed that the ACC is necessary for the aversive component of neuropathic pain [68]. Additionally, the ACC has been implicated in pain expectation in imaging studies [69]. The IC, meanwhile, has been strongly implicated in processing pain intensity and interacts with several other key pain regions, including the PFC, ACC, S2, 
and amygdala (Figure 1). Because of the complexity of the IC's connections with other relevant regions, its role in processing affective or depressive symptoms of pain remains a strong possibility. In addition, IC activity has been tied to both antinociceptive and pronociceptive functions [70].

The hippocampus and amygdala are two additional structures that likely play a role in pain-induced depressive behaviors. The hippocampus, a region known for its role in learning and memory, has been well-studied in the regulation of depressive phenotype. Recent animal studies have shown that cognitive and affective processes are impaired in chronic neuropathic pain conditions and that this impairment corresponds with a decreased hippocampal volume [71]. Neurometabolic changes that can result in decreased serotonin levels in the hippocampus have also been demonstrated to cause depressive symptoms in an inflammatory pain model in rodents [52]. Moreover, studies have demonstrated that paininduced changes in the hippocampus correlate with anxietylike behaviors commonly associated with the depressed state [71]. In contrast to decreased hippocampal volume, neuropathic pain has been observed to increase the volume and neuronal proliferation in both the central and basolateral nuclei of amygdala [72]. Given the well documented role of the amygdala in fear and in mood disorders, the amygdala has been suggested as a strong candidate for mediating depression-like symptoms resulting from pain [73-75]. Indeed, a number of studies have demonstrated that the amygdala is crucial in maintaining anxio-depressive and nocifensive behaviors in persistent inflammatory and neuropathic pain states [76-80].

Recent studies of the mesolimbic pathway, including the PFC, VTA, and NAc, have indicated a prominent role for these regions in pain processing, particularly in the depression-like symptoms resulting from chronic pain. The PFC, VTA, and NAc play crucial roles in reward processing, and these regions are also activated by nociception [81-83]. The PFC-VTA-NAc axis is critical for the maintenance of normal hedonic experience and motivation, and hence this reward circuitry also plays a part in the pathogenesis of depression [56]. A recent study showed that chronic pain induces the synaptic incorporation of calcium permeable $\alpha$-amino-3-hydroxy-5-methyl-4-isoxazolepropionic acid (AMPA) receptors in the NAc and that transmission through these receptors has important antidepressant properties in the chronic pain state [58]. Meanwhile, the PFC has been found to play a role in pain through its connection with the NAc (Figure 1) [23]. It has been shown recently that basal dendrites in the PFC of SNI-treated rodents are longer and have more branches than those of control animals, and spine density is also selectively increased in basal dendrites of these neurons from SNI rats [84]. Thus, changes in the circuit that links the PFC, VTA, and NAc may play an important role in the relationship between pain and depression.

\section{Molecular Mechanisms That Underlie the Long-Term Plasticity of Pain-Induced Depression}

5.1. Glutamate Signaling. The current glutamate hypothesis for depression posits that long lasting alterations in glutamate signaling contribute to the regulation of depressive phenotype [85]. AMPA receptors are the primary mediators of excitatory synaptic transmission, and they are composed of four subunits, GluA1-4. Reduced GluA1 levels in the amygdala, PFC, and hippocampus have been found in several rodent stress models of depression [86-88]. In the NAc, meanwhile, lower levels of GluA2-containing AMPA receptors have been described in depressive states [89, 90]. Several lines of evidence suggest the importance of AMPA receptor signaling in depression. First, GluA1 knockout mice display vulnerability to depression [91]. Second, antidepressants can increase GluA1 and GluA2 expression in the PFC and NAc [92, 93]. Lastly, AMPA potentiators which directly increase AMPA receptor activities have been shown to have antidepressant properties [50].

Glutamate signaling has been studied in animal pain models as well. In the classic PAG-RVM-spinal descending pathway [94-96], neurons from the PAG form glutamatergic projections through AMPA receptors on GABAergic cells in the RVM to inhibit dorsal horn neurons [97]. Not surprisingly, the administration of glutamate into the PAG is known to produce analgesia [98-100]. In the RVM, meanwhile, AMPA receptor upregulation mediates analgesia in inflammatory pain states $[101,102]$, whereas their downregulation in neuropathic pain causes hyperalgesia [103]. Thus, transmission through AMPA receptors is required for the intact PAGRVM descending pathway $[104,105]$. A second pain modulating center that depends on glutamate signaling is the NAc. The NAc provides pain-induced analgesia, in part through its projection to the RVM [106]. Intra-NAc administration of AMPA receptor antagonists, however, can disrupt this paininduced analgesic mechanism [107]. Furthermore, chronic pain has been shown to decrease vesicular glutamate transporter (VGLUT) 1 and 3 levels in the NAc, suggesting a decrease in glutamate signaling in this region [108]. The most direct evidence for the analgesic effects of glutamate signaling comes from a study that showed AMPAkines, positive allosteric modulators for AMPA receptors, have antinociceptive properties in persistent inflammatory and neuropathic pain conditions [53].

At the same time, however, chronic inflammatory pain increases trafficking of GluA1 AMPA receptor subunits but decreases GluA2 delivery [109-111], leading to the formation of GluA2-lacking receptors [112]. Similarly, AMPA receptor signaling in the ACC and amygdala has also been suggested to increase synaptic plasticity and confer hyperalgesia [113-117]. Thus, in chronic pain conditions, AMPA receptor signaling plays both pronociceptive and antinociceptive roles, depending on the target CNS regions.

An emerging number of studies have demonstrated that glutamate signaling also plays an important role in specifically mediating the depressive symptoms of pain. For example, a study on AMPA receptor subunit trafficking showed that chronic neuropathic pain selectively increases GluA1 levels at the synapse of the NAc, leading to the formation of GluA2-lacking, or calcium permeable AMPA receptors (CPARs) [58]. Glutamate transmission through these newly formed CPARs, in turn, relieves the depressive symptoms of pain without altering pain sensitivities. In addition, pharmacologic studies using ketamine and AMPAkines, two classes 
of drugs that increase glutamate signaling through AMPA receptors $[92,118,119]$, have demonstrated that drugs that increase glutamate signaling in the brain can also treat the depressive symptoms of chronic pain [49, 53]. Thus, glutamate signaling, particularly signaling through AMPA receptors, plays a key role in regulating pain, depression, and depression in the context of chronic pain.

5.2. Modulatory Neuropeptides (Serotonin, Dopamine, and Norepinephrine). Modulatory neuropeptides have long been studied in the context of both depression and pain. Norepinephrine (NE) neurons are found in the locus ceruleus (LC), and decreased NE signaling is known to be associated with depression [120-124]. The LC releases NE into multiple regions in the brain, including the cerebral cortex, limbic system, and spinal cord. Originally thought to regulate attention and fight-or-flight responses, the NE system has been shown to affect a wide range of cognitive and affective functions. Activation of the descending modulatory pathway from the RVM and PAG, meanwhile, can release NE into the spinal dorsal horn. The binding of NE to the spinal alpha2 receptors has been found to exert antinociceptive effects [125]. Thus, noradrenergic system can have a profound influence on the pathogenesis of pain and depression.

Dopamine (DA) neurons are located in the VTA. Dysfunctional DA signaling can cause depression [126130]. Dopamine dysfunction has also been associated with increased pain sensitivity in several chronic pain conditions, including headache, fibromyalgia, and osteoarthritis [131134]. Interestingly, Parkinson's disease, which presents a classic hypodopaminergic state, is associated with increased incidence of both depression and chronic pain $[135,136]$. While the molecular mechanism for the role of DA signaling in pain-induced depression remains incompletely characterized, it is thought that dopaminergic signaling in the PFC and NAc is critical for the maintenance of normal hedonic drive, as well as working memory, concentration, and locomotion. Thus, dysfunction of the DA system results in symptoms of anhedonia, reduced concentration, sleep disturbance, and psychomotor retardation, all salient symptoms of paininduced depression $[127,137]$.

Serotonin (5-HT) cells are located in the dorsal and medial raphe nuclei. The role of 5-HT in depression is welldescribed [120,121, 138, 139]. 5-HT is projected widely throughout the brain to modulate synapses as well as the release and function of NE and DA, and its activity in the PFC, ACC, VTA, and NAc is thought to influence mood and affect. In addition, 5-HT has also been shown to be critical for descending modulation of pain [140-144]. Activation of the descending projections from the RVM, which includes nucleus raphe magnus, produces 5-HT release in the spinal dorsal horns [97, 145-148]. The RVM provides both descending inhibition and facilitation of pain, through the activation of "on" and "off" cells, respectively [148-154]. Thus, 5-HT signaling can exert both antidepressant and antinociceptive properties by modulating synaptic connectivity and the other monoamine signaling in various regions in the brain. A recent study examined the role of brain indoleamine 2,3-dioxygenase (IDO1) in the comorbidity of pain and depression [52]. IDO1 is a rate-limiting enzyme in the metabolism of tryptophan, a precursor to serotonin, and IDO1 activity has been linked to decreased 5-HT content. This study found that inhibition of hippocampal IDO1 activity attenuated pain-induced depression, thus providing further evidence that 5-HT signaling can exert control over the comorbidity of pain and depression.

\subsection{Neurotrophic Factors and Neuromodulatory Lipids.} Brain-derived neurotrophic factor (BDNF) promotes the formation of synaptic plasticity [155]. BDNF binds to two receptors on the surface of cells: TrkB and the low-affinity nerve growth factor receptor. $\operatorname{Trk} B$ is a receptor tyrosine kinase, and the binding of BDNF to TrkB promotes the formation of long-term potentiation at synapses as well as de novo neurogenesis. Decreased BDNF levels have been identified in patients who have suffered from major depressive disorder, whereas patients who underwent successful antidepressant treatment have shown increased BDNF levels [156-158]. Elevated BDNF levels have been associated with fibromyalgia, whereas a decreased level has been found in patients with chronic migraine $[159,160]$. BDNF val66met polymorphism, in particular, has been identified in patients with chronic abdominal and pelvic pain $[161,162]$. BDNF has been shown to regulate both peripheral and spinal sensitivity to chronic pain in various animal models [163]. Furthermore, in the hippocampus, decreased BDNF has been found in chronic inflammatory pain states, and this decrease has been shown to be responsible for depression-like behaviors [164]. Thus, by modulating synaptic plasticity throughout the peripheral and central pain circuits, BDNF can alter pain sensitivity and, more importantly, the level of pain-induced depression.

The endocannabinoid system is a signaling system comprising the G-protein coupled cannabinoid $\mathrm{CB} 1$ and $\mathrm{CB} 2$ receptors, their intrinsic lipid ligands, endocannabinoids such as the $\mathrm{N}$-arachidonoyl ethanolamide (anandamide) and the 2-arachidonoyl glycerol, and associated proteins (transporters, biosynthetic, and degradative enzymes) [165]. The $\mathrm{CB} 1$ receptor couples to both $\mathrm{G}_{\mathrm{i} / \mathrm{o}}$ proteins which function to inhibit adenylyl cyclase activity, activate potassium channels, and inhibit voltage-gated calcium channels, while the $\mathrm{CB} 2$ receptor is known to couple to $G_{i}$ proteins. The $C B 1$ receptor is located predominantly on presynaptic axon terminals, and it regulates calcium influx and subsequent neurotransmitter release to influence synaptic plasticity. CB1 knockout mice become anhedonic during chronic mild stress, and they also demonstrate decreased motivation, indicative of the depressive phenotype $[166,167]$. These changes are likely caused by alterations in CB1 signaling that help to maintain normal synaptic efficiency in the PFC, amygdala, hippocampus, and NAc [168-171]. Both CB1 and CB2 receptors are abundantly expressed in motor and limbic regions and in areas that are involved in pain transmission and modulation, including the PAG, RVM, spinal cord dorsal horn, and the peripheral nerve. In the RVM, CB1 signaling can alter the "on" and "off" cell balance to favor descending inhibition. In the spinal 
dorsal horn, it can decrease $N$-methyl-D-aspartic acid or $\mathrm{N}$-methyl-D-aspartate (NMDA) receptor activation and decrease noxious stimulus-evoked firing of wide dynamic range neurons [172]. Endocannabinoid signaling can also inhibit neuropeptide release from primary afferent fibers in response to acute noxious stimulus. Thus, endocannabinoid signaling plays important roles in regulating both depression and pain. Interestingly, a recent study showed that a CB2selective agonist GW405833 specifically relieves depressive symptoms of chronic neuropathic pain in rats, but it has no antidepressant effects in rats that do not experience pain [173]. This finding not only indicates that pain can induce depression, but it provides evidence that pain-induced depression may have unique physiologic and molecular mechanisms.

5.4. Transcriptional, Translational, and Epigenetic Mechanisms. Transcriptional mechanisms have been well studied in animal models of depression, and genome wide arrays have begun to uncover genetic bases for depression in patients who suffer from major depressive disorders. The best characterized transcriptional mechanism controlling depression-like behaviors involves CREB. The role of CREB on depressive symptoms varies depending on the specific brain regions. Increased transcriptional activity in the hippocampus induced by CREB has been demonstrated to have antidepressant effects. In contrast, CREB signaling in the NAc promotes stress susceptibility and induces anhedonic behaviors [174]. Prominent targets for CREB include potassium channels, glutamate receptors, dynorphin, and other neuropeptides [175177]. By acting on these receptors and peptides, CREB can increase the intrinsic excitability of cortical, hippocampal, and accumbal neurons and promote glutamatergic plasticity, which will in turn serve as circuit level regulators for affect and behavior. The role of CREB is well documented in animal pain models as well. A number of studies have shown that CREB signaling in the hippocampus, cortex, and NAc can alter pain sensitivity [178-180]. Furthermore, a recent study demonstrated that CREB signaling in the ACC promotes the negative affective experience of pain, as manifested by conditioned place avoidance [181]. Thus CREB is likely an important mediator of depressive symptoms of pain.

Translational regulators, especially mTOR, have been actively investigated in both pain and depression models in rodents. mTOR signaling in the PFC has been shown to give rise to dendritic growth and upregulation of the synaptic machinery, which underlie the antidepressant effect of ketamine $[92,182]$. Recently, mTOR signaling in the hippocampus has also been found to regulate pain-related synaptic plasticity [183]. Thus, translational regulation provides another level of control for the comorbidity of pain and depression.

In addition to transcriptional and translational control of synapse and neuronal excitability, proteins that posttranslationally modify histone, DNA, and recruit large sets of coactivators or corepressors of genes have come under active scrutiny over the last two decades. Such epigenetic mechanisms have been identified to play significant roles in the pathogenesis and regulation of depression and pain. For example, local inhibition of certain histone deacetylases (HDACs) or DNA methyltransferases (DNMTs) and conversely local activation of histone methyltransferases (HMTs) in the NAc have been found to have antidepressant effects in various animal models of depression [184-186]. Similarly, alterations of HDACs and DNMTs in the cortex and hippocampus have also been implicated in depression-like behaviors [187-189]. Epigenetic mechanisms have been demonstrated to alter pain sensitivity at both spinal and peripheral levels [190]. In addition, studies have begun to reveal that changes in HDACs and DNMTs in the hypothalamus, cortex, and brain stem can regulate both sensory and affective pain behaviors [191-193]. Particularly, altered DNA methylation of the corticotropin releasing-factor genes in the hypothalamicpituitary-adrenal axis has been shown to result in stressinduced pain hypersensitivity, raising the possibility that central epigenetic mechanisms can play a role in the relationship between pain and depression [191].

These molecular mechanisms are summarized in Table 1.

\section{Treatment for the Comorbidity of Pain and Depression}

A line of clinical evidence that supports the close pathological relationship between chronic pain and depression comes from the drugs that can treat both conditions. Currently, two classes of antidepressants, serotonin, and norepinephrine reuptake inhibitors (SNRIs) and tricyclic antidepressants (TCAs) are Federal Drug Administration (FDA) approved for the treatment of depression as well as a variety of chronic pain conditions. Furthermore, experimental treatments, including ketamine and deep brain stimulation, have been demonstrated to have efficacy in treating both pain and depression.

6.1. Serotonin and Norepinephrine Reuptake Inhibitors (SNRIs). Serotonin reuptake inhibitors (SSRIs) and serotonin and norepinephrine reuptake inhibitors (SNRIs) are mainstay treatment options for depression. By inhibiting the reuptake of serotonin, SSRIs can increase the extracellular levels of these neurotransmitters [194]. SNRIs, in addition, increase the level of norepinephrine as well. SSRIs are currently the first-line treatment for depression. While the exact targets for these drugs are not known, it is thought that they exert antidepressant effects by augmenting synaptic plasticity in the cortex, hippocampus, striatum, and a number of other brain regions. In addition, SSRIs can promote neurogenesis in the hippocampus [195]. However, the efficacy of SSRIs in pain has been disappointing, with number needed to treat greater than 15 for most of the drugs in this class. SNRIs, in contrast, have been highly successful in treating a wide range of pain, particularly neuropathic pain, including diabetic neuropathy, postherpetic neuralgia, and fibromyalgia [196-200]. Thus, likely SNRIs modulate the NE signaling pathway in the CNS to decrease pain and pain-induced depression. One possible mechanism is the activation of the descending modulatory pathway from the RVM and PAG to the dorsal horn neurons [125]. On the other hand, there 
TABLE 1: Molecular mechanisms in pain and depression.

\begin{tabular}{|c|c|c|}
\hline Molecular marker & Depression & Pain \\
\hline Glutamate & $\begin{array}{l}\text { (i) Reduced GluA1-containing AMPA receptors in } \\
\text { amygdala, PFC, and hippocampus } \\
\text { (ii) Reduced GluA2-containing AMPA receptors in } \\
\text { NAc } \\
\text { (iii) Ketamine's antidepressant actions likely include } \\
\text { increases in AMPA receptor signaling }\end{array}$ & $\begin{array}{l}\text { (i) AMPA receptor upregulation in RVM mediates } \\
\text { analgesia; AMPA receptor downregulation in RVM } \\
\text { causes hyperalgesia } \\
\text { (ii) Reduced VGLUT1 and } 3 \text { levels in NAc } \\
\text { (iii) Reduced GluA2-containing AMPA receptors in } \\
\text { NAc } \\
\text { (iv) Ketamine's analgesic actions likely due to NMDA } \\
\text { antagonism }\end{array}$ \\
\hline Norepinephrine & Decreased signaling in LC & $\begin{array}{l}\text { Activation of RVM and PAG causes norepinephrine } \\
\text { release and antinociception }\end{array}$ \\
\hline Dopamine & Decreased signaling in VTA and NAc & Decreased signaling in the NAc \\
\hline Serotonin & Altered signaling in PFC, ACC, VTA, and NAc & $\begin{array}{l}\text { Can both inhibit and facilitate pain by projection to off } \\
\text { and on cells in the RVM }\end{array}$ \\
\hline BDNF & Decreased serum levels & $\begin{array}{l}\text { (i) Elevated serum levels in fibromyalgia } \\
\text { (ii) Decreased serum levels in migraine }\end{array}$ \\
\hline Endocannabinoids & CB1 knockout mice display depressive phenotype & $\begin{array}{l}\text { (i) CB1 signaling in the RVM favors descending } \\
\text { inhibition } \\
\text { (ii) CB1 signaling in the spinal dorsal horn decreases } \\
\text { NMDA receptor activation }\end{array}$ \\
\hline CREB & $\begin{array}{l}\text { (i) Increased activity in hippocampus has } \\
\text { antidepressant effects } \\
\text { (ii) Signaling in NAc induces anhedonic behaviors }\end{array}$ & $\begin{array}{l}\text { Signaling in the hippocampus, cortex, and NAc can } \\
\text { alter pain sensitivity }\end{array}$ \\
\hline mTOR & $\begin{array}{l}\text { Signaling in PFC underlies antidepressant effect of } \\
\text { ketamine }\end{array}$ & $\begin{array}{l}\text { Signaling in the hippocampus regulated pain-related } \\
\text { synaptic plasticity }\end{array}$ \\
\hline Epigenetic & $\begin{array}{l}\text { (i) Inhibition of HDACs and DNMTs in NAc has } \\
\text { antidepressant effects } \\
\text { (ii) Activation of HMTs in NAc has antidepressant } \\
\text { effects } \\
\text { (iii) Alterations of HDACs and DNMTs in cortex and } \\
\text { hippocampus implicated in depressive behaviors }\end{array}$ & $\begin{array}{l}\text { Changes in HDACs and DNMTs in hypothalamus, } \\
\text { cortex, and brain stem can regulate sensory and } \\
\text { affective pain behaviors }\end{array}$ \\
\hline
\end{tabular}

is increasing evidence that the pathogenesis of fibromyalgia strongly involves abnormal processing in the brain, and the incidence for the comorbidity of fibromyalgia and depression is particularly high [201, 202]. Thus, SNRIs likely can also alter NE signaling and synaptic transmission in the brain to decrease pain, depression, and other associated affective symptoms in fibromyalgia patients [202]. Currently, duloxetine is the first-line treatment option for fibromyalgia. For neuropathic pain in general, the number needed to treat is approximately 2-5 for SNRIs [203]. It is interesting to note, however, that the dose of SNRIs for chronic pain treatment is approximately half of what is used for the treatment of major depressive disorder.

6.2. Tricyclic Antidepressants (TCAs). Tricyclic antidepressants (TCAs) are an older class of antidepressants. These drugs block the serotonin transporter and norepinephrine transporter to increase the synaptic concentration of these neurotransmitters [194]. Thus, the pharmacologic mechanisms for SNRIs and TCAs are similar. TCAs have been largely replaced by the SSRIs and SNRIs as the first-line treatment for depression due to their more serious side effect profile and poorer tolerability at higher doses. Over the past two decades, however, TCAs have been widely used in the treatment of a number of chronic pain conditions, most notably neuropathic pain conditions [199]. They are used for essentially the same pain syndromes as SNRIs, including diabetic neuropathy, postherpetic neuralgia, and fibromyalgia as well as chronic low back pain with an element of radiculopathy. The number needed to treat pain for the TCAs is comparable to that of the SNRIs [204]. Similar to the SNRIs, the dose of TCAs for chronic pain treatment is less than half of what is used for depression. The commonly used TCAs include amitriptyline, nortriptyline, and desipramine.

6.3. Ketamine. Ketamine is classified as a dissociative anesthetic, and it is FDA approved as an anesthetic as well as an analgesic agent. Ketamine affects the function of a number of receptors and channels. It is known to block NMDA receptors. It is also an agonist for dopamine D2 receptors and blocks dopamine reuptake. More recently, ketamine has been shown to increase presynaptic glutamate release and to 
activate mTOR to promote the translation of GluA1 AMPA receptor units at the postsynaptic site [92]. Recently, ketamine has emerged as a fast onset, long-lasting, and potent antidepressant. A single subanesthetic dose of IV ketamine has rapidly and reproducibly decreased depressive symptoms in treatment-resistant depressed patients, with antidepressant responses detected within 1-2 hours after infusion, maintained in a majority of patients for at least 24 hours, and in some cases for up to 7 days [205-207]. While the mechanism of antidepressant action for ketamine remains incompletely understood, it likely involves an increase in AMPA receptor signaling, an increase in BDNF levels, and an overall increase in synaptic plasticity in the cortex and hippocampus $[92,208$, 209]. In animal studies, a subanesthetic dose of ketamine has been shown to relieve pain-induced depression for up to five days after a single administration [49], and this time frame is comparable to studies of stress-induced depression models as well as human studies of depression. Ketamine has long been used as an analgesic for acute pain. Recently, sub-anesthetic-dose ketamine infusion has been used for the treatment of refractory neuropathic pain syndromes with significant depressive comorbidities, most notably the complex regional pain syndrome [210-213]. In these patients, repeated infusions of subanesthetic doses of ketamine have been shown to effectively treat pain as well as associated affective comorbidities, including depressed mood. In a number of these studies, the effect has lasted weeks to months.

6.4. Future Therapeutic Developments. Despite of these drugs discussed above, pharmacologic options for the comorbidity of pain and depression remain fairly limited. Based on our current understanding of circuit and molecular mechanisms for the comorbidity of pain and depression, however, two future therapeutic approaches hold promise. The first approach is to use neuromodulation (such as deep brain stimulation (DBS) or transcranial magnetic stimulation or even biofeedback or cognitive behavioral therapy) to target the converging circuit pathways in the brain that are responsible for pain as well as depression. Our knowledge of the converging pain and depression circuitry suggests that certain brain regions, including the dorsolateral PFC, hippocampus, and NAc, can be potential targets for neuromodulation. DBS targeting some of these regions, in particular the PFC, can significantly alter long-term neural plasticity and has been under intense and active investigation for refractory depression [214-216]. However, neuromodulation treatment for pain has been limited to spinal cord and peripheral afferent stimulations [217]. In the future, DBS targeting the PFC and NAc should be considered in preclinical and clinical studies for the comorbidity of pain and depression. A second hypothetical therapeutic approach that holds promise is targeting the excitatory neurotransmission that can treat both pain and depression. In this regard, AMPA receptors are ideal targets. A recent study shows that AMPAkines, drugs that potentiate AMPA receptor function, can relieve depressive symptoms of pain [50]. Furthermore, ketamine, which increases AMPA receptor signaling, has also been shown to relieve paininduced depression in animal models [49]. Thus, future clinical studies are needed to further evaluate the efficacy of drugs such as AMPAkines and ketamine in the treatment of comorbidity of pain and depression. Finally, an intriguing class of drugs are HDAC inhibitors which, by modifying genomic expression at a large scale, can profoundly affect both the circuit and molecular basis of pain and depression. HDAC inhibitors have been shown to relieve pain in neuropathic and inflammatory models of pain [151, 218]. They have antidepressant effects in animal models of depression as well [186]. HDAC inhibitors have already been approved for the treatment of some cancers, and the HDAC inhibitor valproic acid is used as a mood stabilizer [154]. Future studies are needed to determine whether inhibition of a single or multiple HDAC isoforms is most efficacious for the treatment of pain and depression.

\section{Conclusion}

Pain and depression are important comorbidities. Both clinical and preclinical studies clearly indicate that pain can cause depression, and that depression can worsen pain behaviors. The CNS undergoes long-term plastic changes associated with chronic pain and depression. Circuit and molecular mechanisms that underlie this plasticity have begun to emerge. Some of the successful current therapeutic approaches have validated these mechanisms, and future therapies based on such mechanistic understanding can be developed to better serve clinical needs.

\section{Conflict of Interests}

The authors declare that there is no conflict of interests regarding the publication of this paper.

\section{Acknowledgment}

This work was supported by the National Institute for General Medical Sciences (GM102691).

\section{References}

[1] M. L. Gillies, L. N. Smith, and W. L. Parry-Jones, "Postoperative pain assessment and management in adolescents," Pain, vol. 79, no. 2-3, pp. 207-215, 1999.

[2] E. C. J. Carr, V. N. Thomas, and J. Wilson-Barnet, "Patient experiences of anxiety, depression and acute pain after surgery: a longitudinal perspective," International Journal of Nursing Studies, vol. 42, no. 5, pp. 521-530, 2005.

[3] R. S. J. Nickinson, T. N. Board, and P. R. Kay, "Post-operative anxiety and depression levels in orthopaedic surgery: a study of 56 patients undergoing hip or knee arthroplasty," Journal of Evaluation in Clinical Practice, vol. 15, no. 2, pp. 307-310, 2009.

[4] J. M. Mossey, E. Mutran, K. Knott, and R. Craik, "Determinants of recovery 12 months after hip fracture: the importance of psychosocial factors," The American Journal of Public Health, vol. 79, no. 3, pp. 279-286, 1989.

[5] H. Kehlet, T. S. Jensen, and C. J. Woolf, "Persistent postsurgical pain: risk factors and prevention," The Lancet, vol. 367, no. 9522, pp. 1618-1625, 2006. 
[6] L. von Knorring, C. Perris, M. Eisemann, U. Eriksson, and H. Perris, "Pain as a symptom in depressive disorders. II. relationship to personality traits as assessed by means of KSP," Pain, vol. 17, no. 4, pp. 377-384, 1983.

[7] P. Lee, M. Zhang, J. P. Hong et al., "Frequency of painful physical symptoms with major depressive disorder in Asia: relationship with disease severity and quality of life," Journal of Clinical Psychiatry, vol. 70, no. 1, pp. 83-91, 2009.

[8] L. Agüera-Ortiz, I. Failde, J. A. Mico, J. Cervilla, and J. J. LópezIbor, "Pain as a symptom of depression: prevalence and clinical correlates in patients attending psychiatric clinics," Journal of Affective Disorders, vol. 130, no. 1-2, pp. 106-112, 2011.

[9] O. Gureje, G. E. Simon, and M. Von Korff, "A cross-national study of the course of persistent pain in primary care," Pain, vol. 92, no. 1-2, pp. 195-200, 2001.

[10] L. J. Carroll, J. D. Cassidy, and P. Côté, "Depression as a risk factor for onset of an episode of troublesome neck and low back pain," Pain, vol. 107, no. 1-2, pp. 134-139, 2004.

[11] M. J. Bair, R. L. Robinson, W. Katon, and K. Kroenke, "Depression and pain comorbidity: a literature review," Archives of Internal Medicine, vol. 163, no. 20, pp. 2433-2445, 2003.

[12] L. S. Williams, W. J. Jones, J. Shen, R. L. Robinson, M. Weinberger, and K. Kroenke, "Prevalence and impact of depression and pain in neurology outpatients," Journal of Neurology, Neurosurgery and Psychiatry, vol. 74, no. 11, pp. 1587-1589, 2003.

[13] P. H. Hilderink, H. Burger, D. J. Deeg, A. T. Beekman, and R. C. Oude Voshaar, "The temporal relation between pain and depression: results from the longitudinal aging study Amsterdam," Psychosomatic Medicine, vol. 74, no. 9, pp. 945-951, 2012.

[14] D. A. Fishbain, R. Cutler, H. L. Rosomoff, and R. S. Rosomoff, "Chronic pain-associated depression: antecedent or consequence of chronic pain? A review," Clinical Journal of Pain, vol. 13, no. 2, pp. 116-137, 1997.

[15] M. M. J. G. Gerrits, N. Vogelzangs, P. Van Oppen, H. W. J. Van Marwijk, H. Van Der Horst, and B. W. J. H. Penninx, "Impact of pain on the course of depressive and anxiety disorders," Pain, vol. 153, no. 2, pp. 429-436, 2012.

[16] M. J. Bair, R. L. Robinson, G. J. Eckert, P. E. Stang, T. W. Croghan, and K. Kroenke, "Impact of pain on depression treatment response in primary care," Psychosomatic Medicine, vol. 66, no. 1, pp. 17-22, 2004.

[17] R. H. Dworkin and M. J. Gitlin, "Clinical aspects of depression in chronic pain patients," Clinical Journal of Pain, vol. 7, no. 2, pp. 79-94, 1991.

[18] M. M. Ohayon and A. F. Schatzberg, "Chronic pain and major depressive disorder in the general population," Journal of Psychiatric Research, vol. 44, no. 7, pp. 454-461, 2010.

[19] P. Schweinhardt and M. C. Bushnell, "Neuroimaging of pain: insights into normal and pathological pain mechanisms," Neuroscience Letters, vol. 520, no. 2, pp. 129-130, 2012.

[20] A. V. Apkarian, M. C. Bushnell, R.-D. Treede, and J.-K. Zubieta, "Human brain mechanisms of pain perception and regulation in health and disease," European Journal of Pain, vol. 9, no. 4, pp. 463-484, 2005.

[21] I. Tracey and E. Johns, "The pain matrix: reloaded or reborn as we image tonic pain using arterial spin labelling," Pain, vol. 148, no. 3, pp. 359-360, 2010.

[22] M. C. Bushnell, M. Čeko, and L. A. Low, "Cognitive and emotional control of pain and its disruption in chronic pain," Nature Reviews Neuroscience, vol. 14, no. 7, pp. 502-511, 2013.
[23] M. N. Baliki, B. Petre, S. Torbey et al., "Corticostriatal functional connectivity predicts transition to chronic back pain," Nature Neuroscience, vol. 15, no. 8, pp. 1117-1119, 2012.

[24] J. A. Hashmi, M. N. Baliki, L. Huang et al., "Shape shifting pain: chronification of back pain shifts brain representation from nociceptive to emotional circuits," Brain, vol. 136, no. 9, pp. 2751-2768, 2013.

[25] K. J. Ressler and H. S. Mayberg, “Targeting abnormal neural circuits in mood and anxiety disorders: from the laboratory to the clinic," Nature Neuroscience, vol. 10, no. 9, pp. 1116-1124, 2007.

[26] S. J. Russo and E. J. Nestler, “The brain reward circuitry in mood disorders," Nature Reviews Neuroscience, vol. 14, no. 9, pp. 609625, 2013.

[27] M. N. Baliki, A. R. Mansour, A. T. Baria, A. V. Apkarian, and Y.-F. Zang, "Functional reorganization of the default mode network across chronic pain conditions," PLoS ONE, vol. 9, no. 9, Article ID e106133, 2014.

[28] L.-L. Zeng, H. Shen, L. Liu et al., "Identifying major depression using whole-brain functional connectivity: a multivariate pattern analysis," Brain, vol. 135, no. 5, pp. 1498-1507, 2012.

[29] A. Ushinsky, L. E. Reinhardt, A. N. Simmons, and I. A. Strigo, "Further evidence of emotional allodynia in unmedicated young adults with major depressive disorder," PLoS ONE, vol. 8, no. 11, Article ID e80507, 2013.

[30] S. Green, M. A. Lambon Ralph, J. Moll et al., "The neural basis of conceptual-emotional integration and its role in major depressive disorder," Social Neuroscience, vol. 8, no. 5, pp. 417-433, 2013.

[31] P. Licznerski and R. S. Duman, "Remodeling of axo-spinous synapses in the pathophysiology and treatment of depression," Neuroscience, vol. 251, pp. 33-50, 2013.

[32] N. I. Eisenberger, M. D. Lieberman, and K. D. Williams, "Does rejection hurt? An fMRI study of social exclusion," Science, vol. 302, no. 5643, pp. 290-292, 2003.

[33] E. Kross, M. G. Berman, W. Mischel, E. E. Smith, and T. D. Wager, "Social rejection shares somatosensory representations with physical pain," Proceedings of the National Academy of Sciences of the United States of America, vol. 108, no. 15, pp. 62706275, 2011.

[34] T. D. Wager, L. Y. Atlas, M. A. Lindquist, M. Roy, C.-W. Woo, and E. Kross, "An fMRI-based neurologic signature of physical pain," The New England Journal of Medicine, vol. 368, no. 15, pp. 1388-1397, 2013.

[35] C. W. Woo, L. Koban, E. Kross et al., "Separate neural representations for physical pain and social rejection," Nature Communications, vol. 5, article 5380, 2014.

[36] M. L. Phillips, L. J. Gregory, S. Cullen et al., "The effect of negative emotional context on neural and behavioural responses to oesophageal stimulation," Brain, vol. 126, Part 3, pp. 669-684, 2003.

[37] E. J. Nestler and S. E. Hyman, "Animal models of neuropsychiatric disorders," Nature Neuroscience, vol. 13, no. 10, pp. 1161$1169,2010$.

[38] T. King, L. Vera-Portocarrero, T. Gutierrez et al., "Unmasking the tonic-aversive state in neuropathic pain," Nature Neuroscience, vol. 12, no. 11, pp. 1364-1366, 2009.

[39] T. A. Green, I. N. Alibhai, C. N. Roybal et al., "Environmental enrichment produces a behavioral phenotype mediated by low cyclic adenosine monophosphate response element binding (CREB) activity in the nucleus accumbens," Biological Psychiatry, vol. 67 , no. 1 , pp. $28-35,2010$. 
[40] M. de Felice, N. Eyde, D. Dodick et al., "Capturing the aversive state of cephalic pain preclinically," Annals of Neurology, vol. 74, no. 2, pp. 257-265, 2013.

[41] J. Vetulani, M. Sansone, L. Baran, and J. Hano, "Opposite action of $\mathrm{m}$-chlorophenylpiperazine on avoidance depression induced by trazodone and pimozide in CD-1 mice," Psychopharmacology, vol. 83, no. 2, pp. 166-168, 1984.

[42] I. Decosterd and C. J. Woolf, "Spared nerve injury: an animal model of persistent peripheral neuropathic pain," Pain, vol. 87, no. 2, pp. 149-158, 2000.

[43] T. J. Brennan, E. P. Vandermeulen, and G. F. Gebhart, "Characterization of a rat model of incisional pain," Pain, vol. 64, no. 3, pp. 493-501, 1996.

[44] K. Ren, J. L. K. Hylden, G. M. Williams, M. A. Ruda, and R. Dubner, "The effects of a non-competitive NMDA receptor antagonist, MK-801, on behavioral hyperalgesia and dorsal horn neuronal activity in rats with unilateral inflammation," Pain, vol. 50, no. 3, pp. 331-344, 1992.

[45] J. T. Hitchens, S. Goldstein, I. Shemano, and J. M. Beiler, "Analgesic effects of irritants in three models of experimentallyinduced pain," Archives Internationales de Pharmacodynamie et de Therapie, vol. 169, no. 2, pp. 384-393, 1967.

[46] X. Wang, S. W. Feng, F. Wang, and S. Xu, "Modeled behavior of neuropathic pain with social defect in rats: a preliminary methodology evaluation," Medical Science Monitor Basic Research, vol. 20, pp. 164-169, 2014.

[47] O. Berton, C. A. McClung, R. J. DiLeone et al., "Essential role of BDNF in the mesolimbic dopamine pathway in social defeat stress," Science, vol. 311, no. 5762, pp. 864-868, 2006.

[48] P. Vachon, M. Millecamps, L. Low et al., "Alleviation of chronic neuropathic pain by environmental enrichment in mice well after the establishment of chronic pain," Behavioral and Brain Functions, vol. 9, no. 1, article 22, 2013.

[49] J. Wang, Y. Goffer, D. Xu et al., "A single subanesthetic dose of ketamine relieves depression-like behaviors induced by neuropathic pain in rats," Anesthesiology, vol. 115, no. 4, pp. 812821, 2011.

[50] P. Skolnick, "AMPA receptors: a target for novel antidepressants?" Biological Psychiatry, vol. 63, no. 4, pp. 347-348, 2008.

[51] M. Shi, J.-Y. Wang, and F. Luo, "Depression shows divergent effects on evoked and spontaneous pain behaviors in rats," Journal of Pain, vol. 11, no. 3, pp. 219-229, 2010.

[52] H. Kim, L. Chen, G. Lim et al., "Brain indoleamine 2,3dioxygenase contributes to the comorbidity of pain and depression," The Journal of Clinical Investigation, vol. 122, no. 8, pp. 2940-2954, 2012.

[53] A. M. Le, M. Lee, C. Su, A. Zou, and J. Wang, "AMPAkines have novel analgesic properties in rat models of persistent neuropathic and inflammatory pain," Anesthesiology, vol. 121, no. 5, pp. 1080-1090, 2014.

[54] C. J. LaBuda and P. N. Fuchs, "A behavioral test paradigm to measure the aversive quality of inflammatory and neuropathic pain in rats," Experimental Neurology, vol. 163, no. 2, pp. 490494, 2000.

[55] J. M. Boyce-Rustay, C. Zhong, R. Kohnken et al., "Comparison of mechanical allodynia and the affective component of inflammatory pain in rats," Neuropharmacology, vol. 58, no. 2, pp. 537543, 2010.

[56] E. J. Nestler and W. A. Carlezon Jr., "The mesolimbic dopamine reward circuit in depression," Biological Psychiatry, vol. 59, no. 12, pp. 1151-1159, 2006.
[57] C. A. von Hehn, R. Baron, and C. J. Woolf, "Deconstructing the neuropathic pain phenotype to reveal neural mechanisms," Neuron, vol. 73, no. 4, pp. 638-652, 2012.

[58] Y. Goffer, D. Xu, S. E. Eberle et al., "Calcium-permeable AMPA receptors in the nucleus accumbens regulate depression-like behaviors in the chronic neuropathic pain state," The Journal of Neuroscience, vol. 33, no. 48, pp. 19034-19044, 2013.

[59] V. K. Kontinen, T. Kauppila, S. Paananen, A. Pertovaara, and E. Kalso, "Behavioural measures of depression and anxiety in rats with spinal nerve ligation-induced neuropathy," Pain, vol. 80, no. 1-2, pp. 341-346, 1999.

[60] T. Suzuki, M. Amata, G. Sakaue et al., "Experimental neuropathy in mice is associated with delayed behavioral changes related to anxiety and depression," Anesthesia and Analgesia, vol. 104, no. 6, pp. 1570-1577, 2007.

[61] F. Denk, S. B. McMahon, and I. Tracey, "Pain vulnerability: a neurobiological perspective," Nature Neuroscience, vol. 17, no. 2, pp. 192-200, 2014.

[62] I. Yalcin, F. Barthas, and M. Barrot, "Emotional consequences of neuropathic pain: insight from preclinical studies," Neuroscience \& Biobehavioral Reviews C, vol. 47, pp. 154-164, 2014.

[63] N. Palomero-Gallagher, B. A. Vogt, A. Schleicher, H. S. Mayberg, and K. Zilles, "Receptor architecture of human cingulate cortex: evaluation of the four-region neurobiological model," Human Brain Mapping, vol. 30, no. 8, pp. 2336-2355, 2009.

[64] P. Rainville, G. H. Duncan, D. D. Price, B. Carrier, and M. C. Bushnell, "Pain affect encoded in human anterior cingulate but not somatosensory cortex," Science, vol. 277, no. 5328, pp. $968-$ 971, 1997.

[65] L. Ning, L.-Q. Ma, Z.-R. Wang, and Y.-W. Wang, "Chronic constriction injury induced long-term changes in spontaneous membrane-potential oscillations in anterior cingulate cortical neurons in vivo," Pain Physician, vol. 16, no. 5, pp. E577-E589, 2013.

[66] D. A. Seminowicz, A. L. Laferriere, M. Millecamps, J. S. C. Yu, T. J. Coderre, and M. C. Bushnell, "MRI structural brain changes associated with sensory and emotional function in a rat model of long-term neuropathic pain," NeuroImage, vol. 47, no. 3, pp. 1007-1014, 2009.

[67] F. Wei and M. Zhuo, "Potentiation of sensory responses in the anterior cingulate cortex following digit amputation in the anaesthetised rat," Journal of Physiology, vol. 532, no. 3, pp. 823833, 2001.

[68] C. Qu, T. King, A. Okun, J. Lai, H. L. Fields, and F. Porreca, "Lesion of the rostral anterior cingulate cortex eliminates the aversiveness of spontaneous neuropathic pain following partial or complete axotomy," Pain, vol. 152, no. 7, pp. 1641-1648, 2011.

[69] C. A. Porro, P. Baraldi, G. Pagnoni et al., "Does anticipation of pain affect cortical nociceptive systems?" Journal of Neuroscience, vol. 22, no. 8, pp. 3206-3214, 2002.

[70] R.-D. Treede, A. V. Apkarian, B. Bromm, J. D. Greenspan, and F. A. Lenz, "Cortical representation of pain: functional characterization of nociceptive areas near the lateral sulcus," Pain, vol. 87, no. 2, pp. 113-119, 2000.

[71] A. A. Mutso, D. Radzicki, M. N. Baliki et al., "Abnormalities in hippocampal functioning with persistent pain," Journal of Neuroscience, vol. 32, no. 17, pp. 5747-5756, 2012.

[72] L. Gonçalves, R. Silva, F. Pinto-Ribeiro et al., "Neuropathic pain is associated with depressive behaviour and induces neuroplasticity in the amygdala of the rat," Experimental Neurology, vol. 213, no. 1, pp. 48-56, 2008. 
[73] L. M. Boyle, "A neuroplasticity hypothesis of chronic stress in the basolateral amygdala," Yale Journal of Biology and Medicine, vol. 86, no. 2, pp. 117-125, 2013.

[74] V. Neugebauer, W. Li, G. C. Bird, and J. S. Han, "The amygdala and persistent pain," Neuroscientist, vol. 10, no. 3, pp. 221-234, 2004.

[75] V. Neugebauer, V. Galhardo, S. Maione, and S. C. Mackey, "Forebrain pain mechanisms," Brain Research Reviews, vol. 60, no. 1, pp. 226-242, 2009.

[76] L. H. Pedersen, J. Scheel-Krüger, and G. Blackburn-Munro, "Amygdala GABA-A receptor involvement in mediating sensory-discriminative and affective-motivational pain responses in a rat model of peripheral nerve injury," Pain, vol. 127, no. 1-2, pp. 17-26, 2007.

[77] B. Myers and B. Greenwood-van Meerveld, "Corticosteroid receptor-mediated mechanisms in the amygdala regulate anxiety and colonic sensitivity," The American Journal of Physiology-Gastrointestinal and Liver Physiology, vol. 292, no. 6, pp. G1622-G1629, 2007.

[78] O. B. Ansah, N. Bourbia, L. Gonçalves, A. Almeida, and A. Pertovaara, "Influence of amygdaloid glutamatergic receptors on sensory and emotional pain-related behavior in the neuropathic rat," Behavioural Brain Research, vol. 209, no. 1, pp. 174-178, 2010.

[79] S. Tanimoto, T. Nakagawa, Y. Yamauchi, M. Minami, and M. Satoh, "Differential contributions of the basolateral and central nuclei of the amygdala in the negative affective component of chemical somatic and visceral pains in rats," European Journal of Neuroscience, vol. 18, no. 8, pp. 2343-2350, 2003.

[80] S. Grégoire and V. Neugebauer, "5-HT2CR blockade in the amygdala conveys analgesic efficacy to SSRIs in a rat model of arthritis pain," Molecular Pain, vol. 9, no. 1, article 41, 2013.

[81] L. Becerra, H. C. Breiter, R. Wise, R. G. Gonzalez, and D. Borsook, "Reward circuitry activation by noxious thermal stimuli," Neuron, vol. 32, no. 5, pp. 927-946, 2001.

[82] M. N. Baliki, A. Mansour, A. T. Baria et al., "Parceling human accumbens into putative core and shell dissociates encoding of values for reward and pain," Journal of Neuroscience, vol. 33, no. 41, pp. 16383-16393, 2013.

[83] M. N. Baliki, P. Y. Geha, H. L. Fields, and A. V. Apkarian, "Predicting value of pain and analgesia: nucleus accumbens response to noxious stimuli changes in the presence of chronic pain," Neuron, vol. 66, no. 1, pp. 149-160, 2010.

[84] A. E. Metz, H. J. Yau, M. V. Centeno, A. V. Apkarian, and M. Martina, "Morphological and functional reorganization of rat medial prefrontal cortex in neuropathic pain," Proceedings of the National Academy of Sciences of the United States of America, vol. 106, no. 7, pp. 2423-2428, 2009.

[85] G. Sanacora, G. Treccani, and M. Popoli, “Towards a glutamate hypothesis of depression: an emerging frontier of neuropsychopharmacology for mood disorders," Neuropharmacology, vol. 62 , no. 1, pp. 63-77, 2012.

[86] A. Chandran, A. H. Iyo, C. S. Jernigan, B. Legutko, M. C. Austin, and B. Karolewicz, "Reduced phosphorylation of the mTOR signaling pathway components in the amygdala of rats exposed to chronic stress," Progress in Neuro-Psychopharmacology and Biological Psychiatry, vol. 40, no. 1, pp. 240-245, 2013.

[87] V. Duric, M. Banasr, C. A. Stockmeier et al., "Altered expression of synapse and glutamate related genes in post-mortem hippocampus of depressed subjects," International Journal of Neuropsychopharmacology, vol. 16, no. 1, pp. 69-82, 2013.
[88] E. Y. Yuen, J. Wei, W. Liu, P. Zhong, X. Li, and Z. Yan, "Repeated stress causes cognitive impairment by suppressing glutamate receptor expression and function in prefrontal cortex," Neuron, vol. 73, no. 5, pp. 962-977, 2012.

[89] B. K. Lim, K. W. Huang, B. A. Grueter, P. E. Rothwell, and R. C. Malenka, "Anhedonia requires MC4R-mediated synaptic adaptations in nucleus accumbens," Nature, vol. 487, no. 7406, pp. 183-189, 2012.

[90] V. Vialou, A. J. Robison, Q. C. LaPlant et al., “ $\Delta$ FosB in brain reward circuits mediates resilience to stress and antidepressant responses," Nature Neuroscience, vol. 13, no. 6, pp. 745-752, 2010.

[91] S. Chourbaji, M. A. Vogt, F. Fumagalli et al., "AMPA receptor subunit 1 (GluR-A) knockout mice model the glutamate hypothesis of depression," The FASEB Journal, vol. 22, no. 9, pp. 31293134, 2008.

[92] N. Li, B. Lee, R.-J. Liu et al., "mTOR-dependent synapse formation underlies the rapid antidepressant effects of NMDA antagonists," Science, vol. 329, no. 5994, pp. 959-964, 2010.

[93] C.-H. Tan, X. He, J. Yang, and W.-Y. Ong, "Changes in AMPA subunit expression in the mouse brain after chronic treatment with the antidepressant maprotiline: a link between noradrenergic and glutamatergic function?" Experimental Brain Research, vol. 170, no. 4, pp. 448-456, 2006.

[94] H. L. Fields, S. D. Anderson, C. H. Clanton, and A. I. Basbaum, "Nucleus raphe magnus: a common mediator of opiate- and stimulus-produced analgesia," Transactions of the American Neurological Association, vol. 101, pp. 208-210, 1976.

[95] A. I. Basbaum and H. L. Fields, "Endogenous pain control systems: brainstem spinal pathways and endorphin circuitry," Annual Review of Neuroscience, vol. 7, pp. 309-338, 1984.

[96] M. M. Heinricher, I. Tavares, J. L. Leith, and B. M. Lumb, "Descending control of nociception: specificity, recruitment and plasticity," Brain Research Reviews, vol. 60, no. 1, pp. 214225, 2009.

[97] M. M. Morgan, K. L. Whittier, D. M. Hegarty, and S. A. Aicher, "Periaqueductal gray neurons project to spinally projecting GABAergic neurons in the rostral ventromedial medulla," Pain, vol. 140, no. 2, pp. 376-386, 2008.

[98] M. M. Behbehani and H. L. Fields, "Evidence that an excitatory connection between the periaqueductal gray and nucleus raphe magnus mediates stimulation produced analgesia," Brain Research, vol. 170, no. 1, pp. 85-93, 1979.

[99] T. S. Jensen and T. L. Yaksh, "Spinal monoamine and opiate systems partly mediate the antinociceptive effects produced by glutamate at brainstem sites," Brain Research, vol. 321, no. 2, pp. 287-297, 1984.

[100] G. Urca, R. L. Nahin, and J. C. Liebeskind, "Glutamateinduced analgesia: blockade and potentiation by naloxone," Brain Research, vol. 192, no. 2, pp. 523-530, 1980.

[101] Y. Guan, W. Guo, S.-P. Zou, R. Dubner, and K. Ren, "Inflammation-induced upregulation of AMPA receptor subunit expression in brain stem pain modulatory circuitry," Pain, vol. 104, no. 1-2, pp. 401-413, 2003.

[102] Y. Guan, W. Guo, M. T. Robbins, R. Dubner, and K. Ren, "Changes in AMPA receptor phosphorylation in the rostral ventromedial medulla after inflammatory hyperalgesia in rats," Neuroscience Letters, vol. 366, no. 2, pp. 201-205, 2004.

[103] Y. C. Ho, J. K. Cheng, and L. C. Chiou, "Hypofunction of glutamatergic neurotransmission in the periaqueductal gray contributes to nerve-injury-induced neuropathic pain," The Journal of Neuroscience, vol. 33, no. 18, pp. 7825-7836, 2013. 
[104] M. O. Urban, S. V. Coutinho, and G. F. Gebhart, "Involvement of excitatory amino acid receptors and nitric oxide in the rostral ventromedial medulla in modulating secondary hyperalgesia produced by mustard oil," Pain, vol. 81, no. 1-2, pp. 45-55, 1999.

[105] Y. Guan, R. Terayama, R. Dubner, and K. Ren, "Plasticity in excitatory amino acid receptor-mediated descending pain modulation after inflammation," Journal of Pharmacology and Experimental Therapeutics, vol. 300, no. 2, pp. 513-520, 2002.

[106] R. W. Gear, K. O. Aley, and J. D. Levine, "Pain-induced analgesia mediated by mesolimbic reward circuits," Journal of Neuroscience, vol. 19, no. 16, pp. 7175-7181, 1999.

[107] M. Ghalandari-Shamami, M. Hassanpour-Ezatti, and A. Haghparast, "Intra-accumbal NMDA but not AMPA/kainate receptor antagonist attenuates WIN55,212-2 cannabinoid receptor agonist-induced antinociception in the basolateral amygdala in a rat model of acute pain," Pharmacology Biochemistry and Behavior, vol. 100, no. 2, pp. 213-219, 2011.

[108] D. S. Tukey, M. Lee, D. Xu et al., "Differential effects of natural rewards and pain on vesicular glutamate transporter expression in the nucleus accumbens," Molecular Brain, vol. 6, no. 1, article 32, 2013.

[109] J.-S. Park, M. Yaster, X. Guan et al., "Role of spinal cord alphaamino-3-hydroxy-5-methyl-4-isoxazolepropionic acid receptors in complete Freund's adjuvant-induced inflammatory pain," Molecular Pain, vol. 4, article 67, 2008.

[110] J.-S. Park, N. Voitenko, R. S. Petralia et al., "Persistent inflammation induces GluR2 internalization via NMDA receptortriggered PKC activation in dorsal horn neurons," The Journal of Neuroscience, vol. 29, no. 10, pp. 3206-3219, 2009.

[111] T. Katano, H. Furue, E. Okuda-Ashitaka et al., "N-ethylmaleimide-sensitive fusion protein (NSF) is involved in central sensitization in the spinal cord through GluR2 subunit composition switch after inflammation," European Journal of Neuroscience, vol. 27, no. 12, pp. 3161-3170, 2008.

[112] B. Hartmann, S. Ahmadi, P. A. Heppenstall et al., "The AMPA receptor subunits GluR-A and GluR-B reciprocally modulate spinal synaptic plasticity and inflammatory pain," Neuron, vol. 44, no. 4, pp. 637-650, 2004.

[113] J. Chen, Y. Song, J. Yang et al., "The contribution of TNF- $\alpha$ in the amygdala to anxiety in mice with persistent inflammatory pain," Neuroscience Letters, vol. 541, pp. 275-280, 2013.

[114] X.-Y. Li, H.-G. Ko, T. Chen et al., "Alleviating neuropathic pain hypersensitivity by inhibiting $\mathrm{PKM} \zeta$ in the anterior cingulate cortex," Science, vol. 330, no. 6009, pp. 1400-1404, 2010.

[115] G. Ji, H. Sun, Y. Fu et al., "Cognitive impairment in pain through amygdala-driven prefrontal cortical deactivation," The Journal of Neuroscience, vol. 30, no. 15, pp. 5451-5464, 2010.

[116] H. Xu, L.-J. Wu, H. Wang et al., "Presynaptic and postsynaptic amplifications of neuropathic pain in the anterior cingulate cortex," Journal of Neuroscience, vol. 28, no. 29, pp. 7445-7453, 2008.

[117] W. Li and V. Neugebauer, "Block of NMDA and non-NMDA receptor activation results in reduced background and evoked activity of central amygdala neurons in a model of arthritic pain," Pain, vol. 110, no. 1-2, pp. 112-122, 2004.

[118] A. C. Arai and M. Kessler, "Pharmacology of ampakine modulators: from AMPA receptors to synapses and behavior," Current Drug Targets, vol. 8, no. 5, pp. 583-602, 2007.

[119] G. Lynch, "Glutamate-based therapeutic approaches: ampakines," Current Opinion in Pharmacology, vol. 6, no. 1, pp. 82-88, 2006.
[120] R. Tissot, "The common pathophysiology of monoaminergic psychoses: a new hypothesis," Neuropsychobiology, vol. 1, no. 4, pp. 243-260, 1975.

[121] H. S. Akiskal and W. T. McKinney Jr., "Depressive disorders: toward a unified hypothesis. Clinical, experimental, genetic, biochemical, and neurophysiological data are integrated," Science, vol. 182, no. 4107, pp. 20-29, 1973.

[122] W. E. Bunney Jr. and J. M. Davis, "Norepinephrine in depressive reactions. A review," Archives of General Psychiatry, vol. 13, no. 6, pp. 483-494, 1965.

[123] P. W. Gold and G. P. Chrousos, "Organization of the stress system and its dysregulation in melancholic and atypical depression: high vs low CRH/NE states," Molecular Psychiatry, vol. 7, no. 3, pp. 254-275, 2002.

[124] B. W. Dunlop, M. E. Kelley, T. C. Mletzko, C. M. Velasquez, W. E. Craighead, and H. S. Mayberg, "Depression beliefs, treatment preference, and outcomes in a randomized trial for major depressive disorder," Journal of Psychiatric Research, vol. 46, no. 3, pp. 375-381, 2012.

[125] A. Pertovaara, "Noradrenergic pain modulation," Progress in Neurobiology, vol. 80, no. 2, pp. 53-83, 2006.

[126] A. Randrup and C. Braestrup, "Uptake inhibition of biogenic amines by newer antidepressant drugs: relevance to the dopamine hypothesis of depression," Psychopharmacology, vol. 53, no. 3, pp. 309-314, 1977.

[127] S. Kapur and J. J. Mann, "Role of the dopaminergic system in depression," Biological Psychiatry, vol. 32, no. 1, pp. 1-17, 1992.

[128] K. M. Pearson-Fuhrhop, E. C. Dunn, S. Mortero et al., "Dopamine genetic risk score predicts depressive symptoms in healthy adults and adults with depression," PLOS ONE, vol. 9, no. 5, Article ID e93772, 2014.

[129] A. K. Friedman, J. J. Walsh, B. Juarez et al., "Enhancing depression mechanisms in midbrain dopamine neurons achieves homeostatic resilience," Science, vol. 344, no. 6181, pp. 313-319, 2014.

[130] S. Moriam and M. E. Sobhani, "Epigenetic effect of chronic stress on dopamine signaling and depression," Genetics \& Epigenetics, vol. 5, pp. 11-16, 2013.

[131] P. Barbanti, L. Fofi, C. Aurilia, and G. Egeo, "Dopaminergic symptoms in migraine," Neurological Sciences, vol. 34, supplement 1, pp. S67-S70, 2013.

[132] S. Gürsoy, E. Erdal, H. Herken, E. Madenci, B. Alaşehirli, and N. Erdal, "Significance of catechol-O-methyltransferase gene polymorphism in fibromyalgia syndrome," Rheumatology International, vol. 23, no. 3, pp. 104-107, 2003.

[133] G. Vargas-Alarcón, J.-M. Fragoso, D. Cruz-Robles et al., "Catechol-O-methyltransferase gene haplotypes in Mexican and Spanish patients with fibromyalgia," Arthritis Research and Therapy, vol. 9, no. 5, article R110, 2007.

[134] L. Diatchenko, G. D. Slade, A. G. Nackley et al., "Genetic basis for individual variations in pain perception and the development of a chronic pain condition," Human Molecular Genetics, vol. 14, no. 1, pp. 135-143, 2005.

[135] J. L. Cummings and D. L. Masterman, "Depression in patients with Parkinson's disease," International Journal of Geriatric Psychiatry, vol. 14, no. 9, pp. 711-718, 1999.

[136] A. Conte, N. Khan, G. Defazio, J. C. Rothwell, and A. Berardelli, "Pathophysiology of somatosensory abnormalities in Parkinson disease," Nature Reviews Neurology, vol. 9, no. 12, pp. 687-697, 2013. 
[137] P. H. Finan and M. T. Smith, "The comorbidity of insomnia, chronic pain, and depression: dopamine as a putative mechanism," Sleep Medicine Reviews, vol. 17, no. 3, pp. 173-183, 2013.

[138] P. R. Albert, F. Vahid-Ansari, and C. Luckhart, "Serotoninprefrontal cortical circuitry in anxiety and depression phenotypes: pivotal role of pre- and post-synaptic 5-HT1A receptor expression," Frontiers in Behavioral Neuroscience, vol. 8, article 199, 2014.

[139] Z. M. Ignácio, G. Z. Réus, H. M. Abelaira, and J. Quevedo, "Epigenetic and epistatic interactions between serotonin transporter and brain-derived neurotrophic factor genetic polymorphism: insights in depression," Neuroscience, vol. 275, pp. 455-468, 2014.

[140] A. I. Basbaum and H. L. Fields, "Endogenous pain control mechanisms: review and hypothesis," Annals of Neurology, vol. 4, no. 5, pp. 451-462, 1978.

[141] S. Potrebic, A. H. Ahn, K. Skinner, H. L. Fields, and A. I. Basbaum, "Peptidergic nociceptors of both trigeminal and dorsal root ganglia express serotonin 1D receptors: implications for the selective antimigraine action of triptans," Journal of Neuroscience, vol. 23, no. 34, pp. 10988-10997, 2003.

[142] E. Horjales-Araujo, D. Demontis, E. K. Lund et al., "Polymorphism in serotonin receptor $3 \mathrm{~B}$ is associated with pain catastrophizing," PLoS ONE, vol. 8, no. 11, Article ID e78889, 2013.

[143] M. Okubo, A. Castro, W. Guo et al., "Transition to persistent orofacial pain after nerve injury involves supraspinal serotonin mechanisms," Journal of Neuroscience, vol. 33, no. 12, pp. 51525161, 2013.

[144] L. Bardin, "The complex role of serotonin and 5-HT receptors in chronic pain," Behavioural Pharmacology, vol. 22, no. 5-6, pp. 390-404, 2011.

[145] G. Kato, T. Yasaka, T. Katafuchi et al., "Direct GABAergic and glycinergic inhibition of the substantia gelatinosa from the rostral ventromedial medulla revealed by in vivo patch-clamp analysis in rats," Journal of Neuroscience, vol. 26, no. 6, pp. 17871794, 2006.

[146] F. Wei, R. Dubner, S. Zou et al., "Molecular depletion of descending serotonin unmasks its novel facilitatory role in the development of persistent pain," Journal of Neuroscience, vol. 30, no. 25, pp. 8624-8636, 2010.

[147] D. Le Bars, A. H. Dickenson, and J. M. Besson, "Microinjection of morphine within nucleus raphe magnus and dorsal horn neurone activities related to nociception in the rat," Brain Research, vol. 189, no. 2, pp. 467-481, 1980.

[148] L. Denke and D. M. Barnes, "An ethnography of chronic pain in veteran enlisted women," Pain Management Nursing, vol. 14, no. 4, pp. e189-e195, 2013.

[149] C. M. Haws, A. M. Williamson, and H. L. Fields, "Putative nociceptive modulatory neurons in the dorsolateral pontomesencephalic reticular formation," Brain Research, vol. 483, no. 2, pp. 272-282, 1989.

[150] S. G. Khasabov, P. Malecha, J. Noack et al., "Activation of rostral ventromedial medulla neurons by noxious stimulation of cutaneous and deep craniofacial tissues," Journal of Neurophysiology, vol. 113, no. 1, pp. 14-22, 2015.

[151] F. Denk, W. Huang, B. Sidders et al., "HDAC inhibitors attenuate the development of hypersensitivity in models of neuropathic pain," Pain, vol. 154, no. 9, pp. 1668-1679, 2013.

[152] M. Crow, F. Denk, and S. B. McMahon, "Genes and epigenetic processes as prospective pain targets," Genome Medicine, vol. 5, no. 2, article 12, 2013.
[153] A. Lukas, B. Mayer, D. Fialová et al., "Pain characteristics and pain control in european nursing homes: cross-sectional and longitudinal results from the services and health for elderly in long term care (SHELTER) study," Journal of the American Medical Directors Association, vol. 14, no. 6, pp. 421-428, 2013.

[154] M. Schroeder, M. O. Krebs, S. Bleich, and H. Frieling, "Epigenetics and depression: current challenges and new therapeutic options," Current Opinion in Psychiatry, vol. 23, no. 6, pp. 588592, 2010.

[155] J. C. Arévalo, D. B. Pereira, H. Yano, K. K. Teng, and M. V. Chao, "Identification of a switch in neurotrophin signaling by selective tyrosine phosphorylation," The Journal of Biological Chemistry, vol. 281, no. 2, pp. 1001-1007, 2006.

[156] F. Boulle, D. L. A. van den Hove, S. B. Jakob et al., "Epigenetic regulation of the BDNF gene: implications for psychiatric disorders," Molecular Psychiatry, vol. 17, no. 6, pp. 584-596, 2012.

[157] S. Sen, R. Duman, and G. Sanacora, "erum brain-derived neurotrophic factor, depression, and antidepressant medications: meta-analyses and implications," Biological Psychiatry, vol. 64, no. 6, pp. 527-532, 2008.

[158] F. Karege, G. Perret, G. Bondolfi, M. Schwald, G. Bertschy, and J.-M. Aubry, "Decreased serum brain-derived neurotrophic factor levels in major depressed patients," Psychiatry Research, vol. 109, no. 2, pp. 143-148, 2002.

[159] C. Laske, E. Stransky, G. W. Eschweiler et al., "Increased BDNF serum concentration in fibromyalgia with or without depression or antidepressants," Journal of Psychiatric Research, vol. 41, no. 7, pp. 600-605, 2007.

[160] F. Blandini, L. Rinaldi, C. Tassorelli et al., "Peripheral levels of BDNF and NGF in primary headaches," Cephalalgia, vol. 26, no. 2, pp. 136-142, 2006.

[161] L. C. Lee, C.-H. Tu, L.-F. Chen et al., "Association of brainderived neurotrophic factor gene Val66Met polymorphism with primary dysmenorrhea," PLOS ONE, vol. 9, no. 11, Article ID e112766, 2014.

[162] S. Y. Reddy, N. A. Rasmussen, N. H. Fourie et al., "Sleep quality, BDNF genotype and gene expression in individuals with chronic abdominal pain," BMC Medical Genomics, vol. 7, no. 1, article 61, 2014.

[163] A. Latremoliere and C. J. Woolf, "Central sensitization: a generator of pain hypersensitivity by central neural plasticity," The Journal of Pain, vol. 10, no. 9, pp. 895-926, 2009.

[164] V. Duric and K. E. McCarson, "Persistent pain produces stress-like alterations in hippocampal neurogenesis and gene expression," Journal of Pain, vol. 7, no. 8, pp. 544-555, 2006.

[165] S. Maione, B. Costa, and V. di Marzo, "Endocannabinoids: a unique opportunity to develop multitarget analgesics," Pain, vol. 154, supplement 1, pp. S87-S93, 2013.

[166] M. Martin, C. Ledent, M. Parmentier, R. Maldonado, and O. Valverde, "Involvement of CB1 cannabinoid receptors in emotional behaviour," Psychopharmacology, vol. 159, no. 4, pp. 379387, 2002.

[167] M. A. Steiner, K. Wanisch, K. Monory et al., "Impaired cannabinoid receptor type 1 signaling interferes with stress-coping behavior in mice," Pharmacogenomics Journal, vol. 8, no. 3, pp. 196-208, 2008.

[168] T. Rubino, D. Vigano', N. Realini et al., "Chronic delta 9tetrahydrocannabinol during adolescence provokes sex-dependent changes in the emotional profile in adult rats: behavioral and biochemical correlates," Neuropsychopharmacology, vol. 33, no. 11, pp. 2760-2771, 2008. 
[169] C. G. Reich, M. E. Taylor, and M. M. McCarthy, "Differential effects of chronic unpredictable stress on hippocampal CB1 receptors in male and female rats," Behavioural Brain Research, vol. 203, no. 2, pp. 264-269, 2009.

[170] M. Bortolato, R. A. Mangieri, J. Fu et al., "Antidepressant-like activity of the fatty acid amide hydrolase inhibitor URB597 in a rat model of chronic mild stress," Biological Psychiatry, vol. 62, no. 10, pp. 1103-1110, 2007.

[171] M. N. Hill, E. J. Carrier, R. J. McLaughlin et al., "Regional alterations in the endocannabinoid system in an animal model of depression: effects of concurrent antidepressant treatment," Journal of Neurochemistry, vol. 106, no. 6, pp. 2322-2336, 2008.

[172] D. R. Sagar, A. G. Gaw, B. N. Okine et al., "Dynamic regulation of the endocannabinoid system: implications for analgesia," Molecular Pain, vol. 5, article 59, 2009.

[173] B. Hu, H. Doods, R.-D. Treede, and A. Ceci, "Depression-like behaviour in rats with mononeuropathy is reduced by the CB2selective agonist GW405833," Pain, vol. 143, no. 3, pp. 206-212, 2009.

[174] W. A. Carlezon Jr., R. S. Duman, and E. J. Nestler, “The many faces of CREB," Trends in Neurosciences, vol. 28, no. 8, pp. 436445, 2005.

[175] M. R. Bruchas, B. B. Land, and C. Chavkin, "The dynorphin/ kappa opioid system as a modulator of stress-induced and proaddictive behaviors," Brain Research, vol. 1314, pp. 44-55, 2010.

[176] C. A. McClung and E. J. Nestler, "Regulation of gene expression and cocaine reward by CREB and $\triangle$ FosB," Nature Neuroscience, vol. 6, no. 11, pp. 1208-1215, 2003.

[177] D. L. Wallace, M.-H. Han, D. L. Graham et al., "CREB regulation of nucleus accumbens excitability mediates social isolationinduced behavioral deficits," Nature Neuroscience, vol. 12, no. 2, pp. 200-209, 2009.

[178] V. Duric and K. E. McCarson, "Neurokinin-1 (NK-1) receptor and brain-derived neurotrophic factor (BDNF) gene expression is differentially modulated in the rat spinal dorsal horn and hippocampus during inflammatory pain," Molecular Pain, vol. 3, article 32, 2007.

[179] M. Barrot, J. D. A. Olivier, L. I. Perrotti et al., "CREB activity in the nucleus accumbens shell controls gating of behavioral responses to emotional stimuli," Proceedings of the National Academy of Sciences of the United States of America, vol. 99, no. 17, pp. 11435-11440, 2002.

[180] G. Descalzi, H. Fukushima, A. Suzuki, S. Kida, and M. Zhuo, "Genetic enhancement of neuropathic and inflammatory pain by forebrain upregulation of CREB-mediated transcription," Molecular Pain, vol. 8, article 90, 2012.

[181] H. Cao, Y.-J. Gao, W.-H. Ren et al., "Activation of extracellular signal-regulated kinase in the anterior cingulate cortex contributes to the induction and expression of affective pain," Journal of Neuroscience, vol. 29, no. 10, pp. 3307-3321, 2009.

[182] O. H. Miller, L. Yang, C.-C. Wang et al., "GluN2B-containing NMDA receptors regulate depression-like behavior and are critical for the rapid antidepressant actions of ketamine," eLife, vol. 3, Article ID e03581, 2014.

[183] D. Lyu, W. Yu, N. Tang et al., "The mTOR signaling pathway regulates pain-related synaptic plasticity in rat entorhinalhippocampal pathways," Molecular Pain, vol. 9, no. 1, article 64, 2013.

[184] S. A. Golden, D. J. Christoffel, M. Heshmati et al., "Epigenetic regulation of RAC1 induces synaptic remodeling in stress disorders and depression," Nature Medicine, vol. 19, no. 3, pp. 337-344, 2013.
[185] H. E. Covington III, I. Maze, H. Sun et al., "A role for repressive histone methylation in cocaine-induced vulnerability to stress," Neuron, vol. 71, no. 4, pp. 656-670, 2011.

[186] H. E. Covington III, I. Maze, Q. C. LaPlant et al., "Antidepressant actions of histone deacetylase inhibitors," Journal of Neuroscience, vol. 29, no. 37, pp. 11451-11460, 2009.

[187] F. A. Schroeder, M. C. Lewis, D. M. Fass et al., "A selective HDAC 1/2 inhibitor modulates chromatin and gene expression in brain and alters mouse behavior in two mood-related tests," PLoS ONE, vol. 8, no. 8, Article ID e71323, 2013.

[188] D. L. A. van den Hove, G. Kenis, A. Brass et al., "Vulnerability versus resilience to prenatal stress in male and female rats; implications from gene expression profiles in the hippocampus and frontal cortex," European Neuropsychopharmacology, vol. 23, no. 10, pp. 1226-1246, 2013.

[189] M. O. Poulter, L. Du, I. C. G. Weaver et al., "GABAA receptor promoter hypermethylation in suicide brain: implications for the involvement of epigenetic processes," Biological Psychiatry, vol. 64, no. 8, pp. 645-652, 2008.

[190] G. Bai, K. Ren, and R. Dubner, "Epigenetic regulation of persistent pain," Translational Research, vol. 165, no. 1, pp. 177-199, 2015.

[191] L. Tran, A. Chaloner, A. H. Sawalha, and B. G. van-Meerveld, "Importance of epigenetic mechanisms in visceral pain induced by chronic water avoidance stress," Psychoneuroendocrinology, vol. 38, no. 6, pp. 898-906, 2013.

[192] B. G. Oertel, A. Doehring, B. Roskam et al., "Genetic-epigenetic interaction modulates $\mu$-opioid receptor regulation," Human Molecular Genetics, vol. 21, no. 21, pp. 4751-4760, 2012.

[193] Z. Zhang, Y.-Q. Cai, F. Zou, B. Bie, and Z. Z. Pan, "Epigenetic suppression of GAD65 expression mediates persistent pain," Nature Medicine, vol. 17, no. 11, pp. 1448-1455, 2011.

[194] J. C. Fournier, R. J. DeRubeis, S. D. Hollon et al., "Antidepressant drug effects and depression severity: a patient-level metaanalysis," Journal of the American Medical Association, vol. 303, no. 1, pp. 47-53, 2010.

[195] L. Santarelli, M. Saxe, C. Gross et al., "Requirement of hippocampal neurogenesis for the behavioral effects of antidepressants," Science, vol. 301, no. 5634, pp. 805-809, 2003.

[196] L. M. Arnold, "Duloxetine and other antidepressants in the treatment of patients with fibromyalgia," Pain Medicine, vol. 8, supplement 2, pp. S63-S74, 2007.

[197] M. J. Ormseth, B. A. Scholz, and C. S. Boomershine, "Duloxetine in the management of diabetic peripheral neuropathic pain," Patient Preference and Adherence, vol. 5, pp. 343-356, 2011.

[198] M. P. Lunn, R. A. Hughes, and P. J. Wiffen, "Duloxetine for treating painful neuropathy, chronic pain or fibromyalgia," Cochrane Database of Systematic Reviews, vol. 1, Article ID CD007115, 2014.

[199] N. Attal, G. Cruccu, R. Baron et al., "EFNS guidelines on the pharmacological treatment of neuropathic pain: 2010 revision," European Journal of Neurology, vol. 17, no. 9, pp. 1113-1123, 2010.

[200] C. S. Zin, L. M. Nissen, M. T. Smith, J. P. O’Callaghan, and B. J. Moore, "An update on the pharmacological management of post-herpetic neuralgia and painful diabetic neuropathy," CNS Drugs, vol. 22, no. 5, pp. 417-422, 2008.

[201] M. di Tella and L. Castelli, "Alexithymia and fibromyalgia: clinical evidence," Frontiers in Psychology, vol. 4, article 909, 2013. 
[202] M. Bernik, T. P. A. Sampaio, and L. Gandarela, "Fibromyalgia comorbid with anxiety disorders and depression: combined medical and psychological treatment," Current Pain and Headache Reports, vol. 17, no. 9, article 358, 2013.

[203] R. A. Moore, N. Cai, V. Skljarevski, and T. R. Tölle, "Duloxetine use in chronic painful conditions-individual patient data responder analysis," European Journal of Pain (United Kingdom), vol. 18, no. 1, pp. 67-75, 2014.

[204] N. B. Finnerup, S. H. Sindrup, and T. S. Jensen, "The evidence for pharmacological treatment of neuropathic pain," Pain, vol. 150, no. 3, pp. 573-581, 2010.

[205] R. Machado-Vieira, G. Salvadore, N. DiazGranados, and C. A. Zarate Jr., "Ketamine and the next generation of antidepressants with a rapid onset of action," Pharmacology and Therapeutics, vol. 123, no. 2, pp. 143-150, 2009.

[206] R. M. Berman, A. Cappiello, A. Anand et al., "Antidepressant effects of ketamine in depressed patients," Biological Psychiatry, vol. 47, no. 4, pp. 351-354, 2000.

[207] C. A. Zarate Jr., J. B. Singh, P. J. Carlson et al., "A randomized trial of an N-methyl-D-aspartate antagonist in treatment-resistant major depression," Archives of General Psychiatry, vol. 63, no. 8, pp. 856-864, 2006.

[208] S. Maeng, C. A. Zarate Jr., J. Du et al., "Cellular mechanisms underlying the antidepressant effects of ketamine: role of alphaamino-3-hydroxy-5-methylisoxazole-4-propionic acid receptors," Biological Psychiatry, vol. 63, no. 4, pp. 349-352, 2008.

[209] A. E. Autry, M. Adachi, E. Nosyreva et al., "NMDA receptor blockade at rest triggers rapid behavioural antidepressant responses," Nature, vol. 475, no. 7354, pp. 91-95, 2011.

[210] T. Ushida, T. Tani, T. Kanbara, V. S. Zinchuk, M. Kawasaki, and H. Yamamoto, "Analgesic effects of ketamine ointment in patients with complex regional pain syndrome type 1," Regional Anesthesia and Pain Medicine, vol. 27, no. 5, pp. 524-528, 2002.

[211] M. J. Sigtermans, J. J. van Hilten, M. C. R. Bauer et al., "Ketamine produces effective and long-term pain relief in patients with Complex Regional Pain Syndrome Type 1," Pain, vol. 145, no. 3, pp. 304-311, 2009.

[212] G. E. Correll, J. Maleki, E. J. Gracely, J. J. Muir, and R. E. Harbut, "Subanesthetic ketamine infusion therapy: a retrospective analysis of a novel therapeutic approach to complex regional pain syndrome," Pain Medicine, vol. 5, no. 3, pp. 263-275, 2004.

[213] R. J. Schwartzman, G. M. Alexander, J. R. Grothusen, T. Paylor, E. Reichenberger, and M. Perreault, "Outpatient intravenous ketamine for the treatment of complex regional pain syndrome: a double-blind placebo controlled study," Pain, vol. 147, no. 1-3, pp. 107-115, 2009.

[214] P. E. Holtzheimer, M. E. Kelley, R. E. Gross et al., "Subcallosal cingulate deep brain stimulation for treatment-resistant unipolar and bipolar depression," Archives of General Psychiatry, vol. 69, no. 2, pp. 150-158, 2012.

[215] P. Riva-Posse, P. E. Holtzheimer, S. J. Garlow, and H. S. Mayberg, "Practical considerations in the development and refinement of subcallosal cingulate white matter deep brain stimulation for treatment-resistant depression," World Neurosurgery, vol. 80, no. 3-4, pp. S27.e25-S27.e34, 2013.

[216] P. Riva-Posse, K. S. Choi, P. E. Holtzheimer et al., "Defining critical white matter pathways mediating successful subcallosal cingulate deep brain stimulation for treatment-resistant depression," Biological Psychiatry, vol. 76, no. 12, pp. 963-969, 2014.
[217] T. R. Deer, N. Mekhail, D. Provenzano et al., "The appropriate use of neurostimulation: avoidance and treatment of complications of neurostimulation therapies for the treatment of chronic pain," Neuromodulation, vol. 17, no. 6, pp. 571-598, 2014.

[218] F. Denk and S. McMahon, "Chronic pain: emerging evidence for the involvement of epigenetics," Neuron, vol. 73, no. 3, pp. 435444, 2012. 

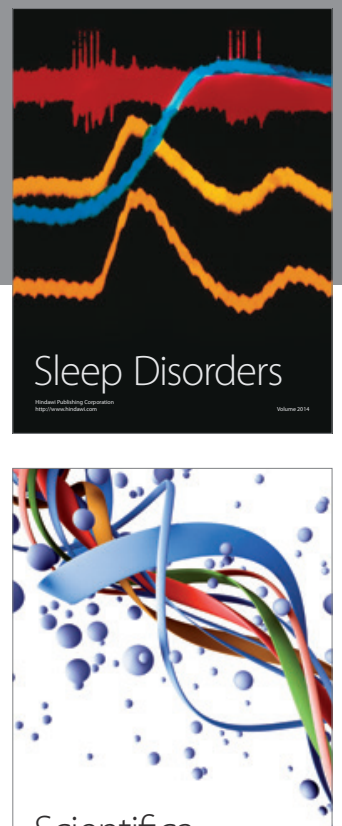

Scientifica
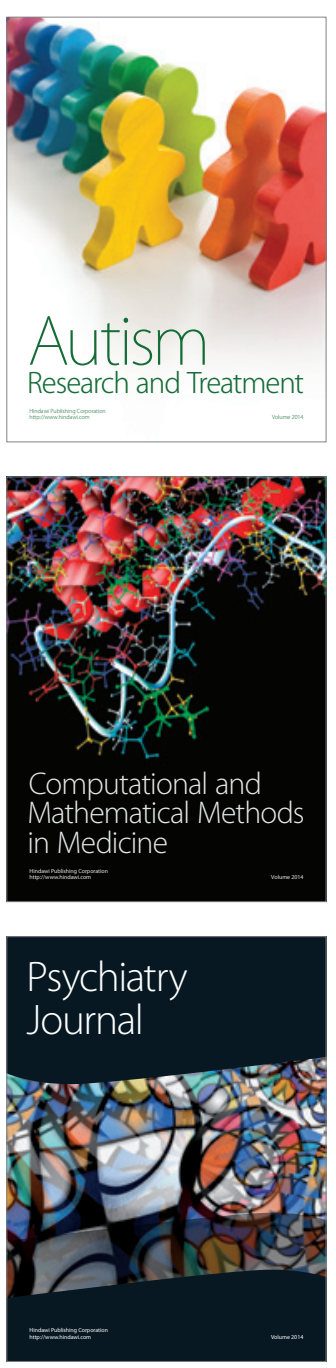
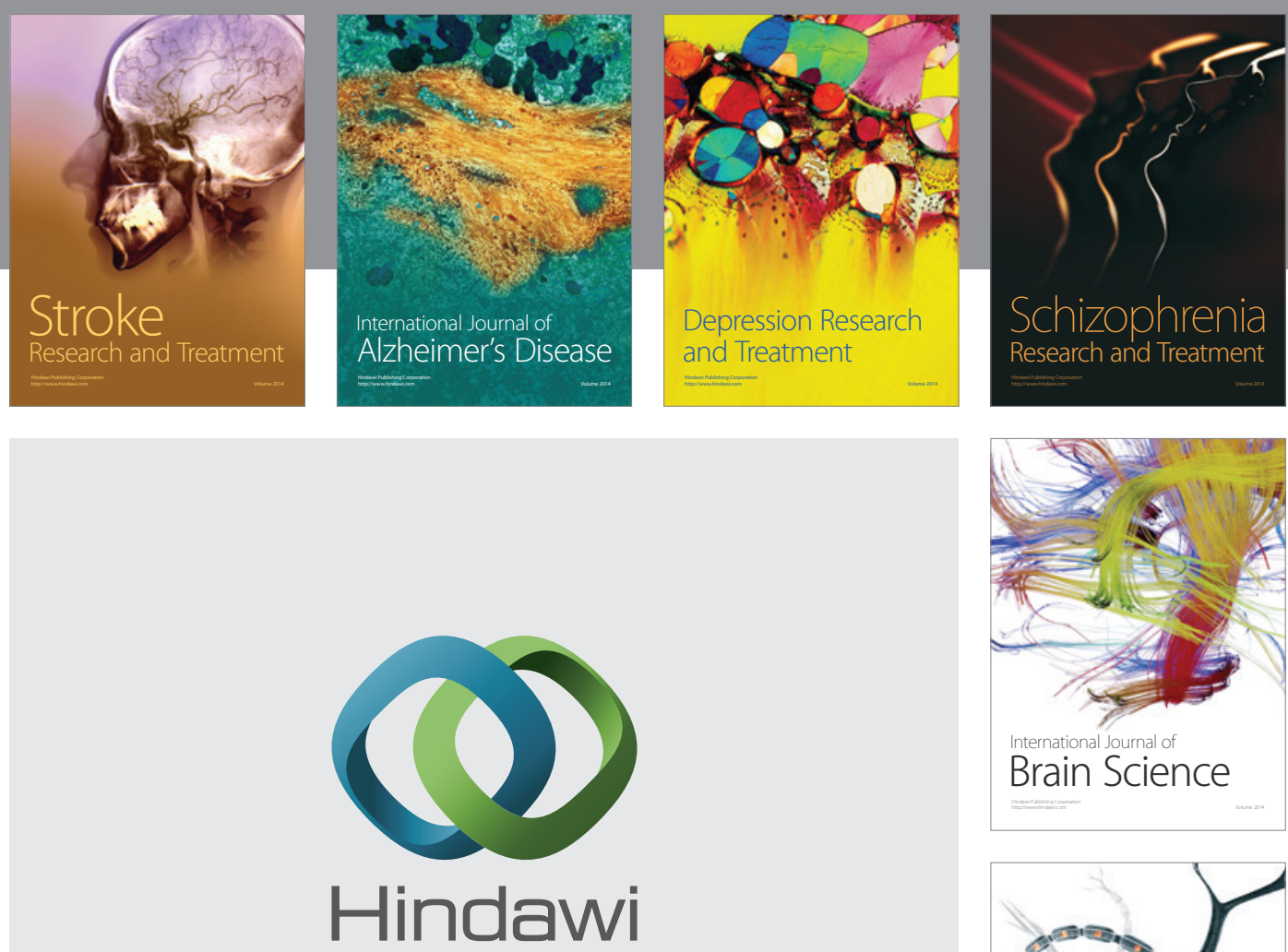

Submit your manuscripts at

http://www.hindawi.com
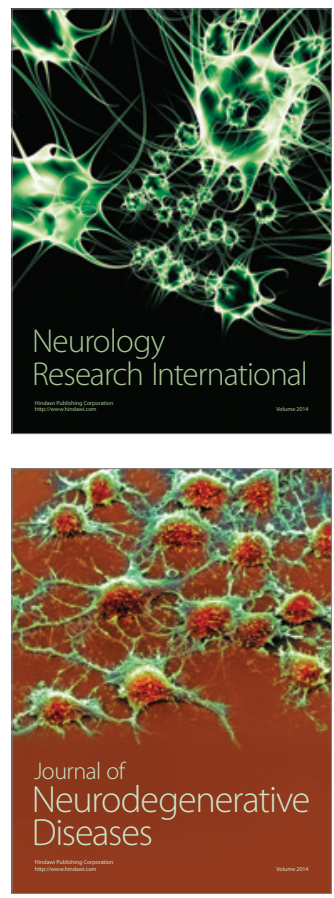

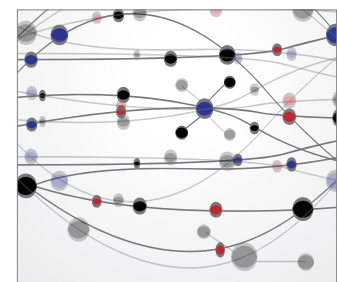

The Scientific World Journal
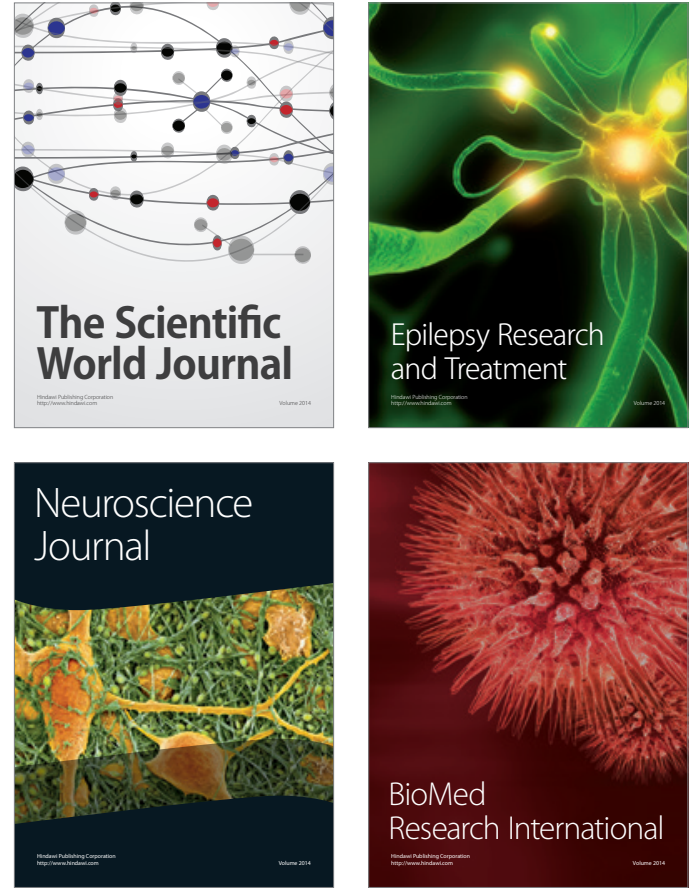

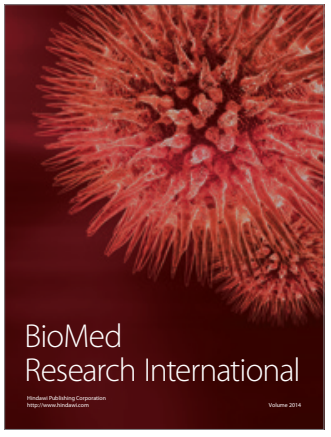

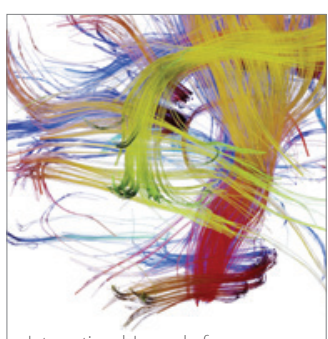

Brain Science

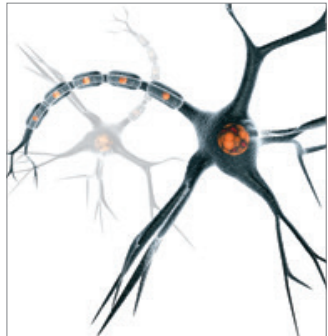

Neural Plasticity
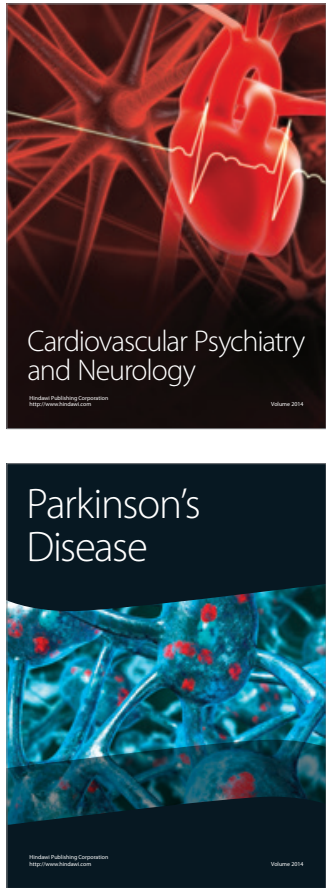